\title{
OPEN Architecting functionalized carbon microtube/carrollite nanocomposite demonstrating significant microwave characteristics
}

\begin{abstract}
Reza Peymanfar ${ }^{1,2 \bowtie}$, Elnaz Selseleh-Zakerin ${ }^{2}$, Ali Ahmadi² \& Seyed Hassan Tavassoli ${ }^{1 \bowtie}$
Biomass-derived materials have recently received considerable attention as lightweight, low-cost, and green microwave absorbers. On the other hand, sulfide nanostructures due to their narrow band gaps have demonstrated significant microwave characteristics. In this research, carbon microtubes were fabricated using a biowaste and then functionalized by a novel complementary solvothermal and sonochemistry method. The functionalized carbon microtubes (FCMT) were ornamented by $\mathrm{CuCO}_{2} \mathrm{~S}_{4}$ nanoparticles as a novel spinel sulfide microwave absorber. The prepared structures illustrated narrow energy band gap and deposition of the sulfide structures augmented the polarizability, desirable for dielectric loss and microwave attenuation. Eventually, the architected structures were blended by polyacrylonitrile (PAN) to estimate their microwave absorbing and antibacterial characteristics. The antibacterial properties against Gram-negative Escherichia coli $(E$. coli) and Gram-positive Staphylococcus aureus (S. aureus) were scrupulously assessed. Noteworthy, the maximum reflection loss (RL) of the $\mathrm{CuCO}_{2} \mathrm{~S}_{4} / \mathrm{PAN}$ with a thickness of $1.75 \mathrm{~mm}$ was $61.88 \mathrm{~dB}$ at $11.60 \mathrm{GHz}$, while the architected FCMT/PAN composite gained a broadband efficient bandwidth as wide as $7.91 \mathrm{GHz}$ $(\mathrm{RL}>10 \mathrm{~dB})$ and $3.25 \mathrm{GHz}(\mathrm{RL}>20 \mathrm{~dB})$ with a thickness of $2.00 \mathrm{~mm}$. More significantly, FCMT/CuCo $\mathrm{S}_{4} /$ PAN demonstrated an efficient bandwidth of $2.04 \mathrm{GHz}(\mathrm{RL}>20 \mathrm{~dB}$ ) with only $1.75 \mathrm{~mm}$ in thickness. Interestingly, $\mathrm{FCMT} / \mathrm{CuCO}_{2} \mathrm{~S}_{4} / \mathrm{PAN}$ and $\mathrm{CuCO}_{2} \mathrm{~S}_{4} / \mathrm{PAN}$ composites demonstrated an electromagnetic interference shielding efficiency of more than 90 and $97 \%$ at the entire $x$ and ku-band frequencies, respectively.
\end{abstract}

The benefits of microwave absorbing materials are clear to anyone caring about his/her health against the harmful electromagnetic waves, emitted from the electronic devices surrounding us in our inescapable mechanical life. The carcinogenicity, reproductive toxicity, genotoxicity, brain tissue injury, neurological damage, and other health hazards associated with microwave have been reported, originated from the human exposure to radiofrequency radiation, known as non-ionizing radiation $(30 \mathrm{kHz}-300 \mathrm{GHz})$, which threaten human and any living $\operatorname{species}^{1-6}$. Accordingly, microwave absorbing materials have been the hotspot owing to their significant importance in the healthcare, industrial, and military fields. The fabricated microwave absorbing materials can essentially promote our health by loading them into textiles, building materials, and dyes, protecting us against harmful radiations. One of the essential aspects to take into account is the biocompatibility of the employed materials in microwave absorbers, diminishing secondary health damages ${ }^{7,8}$. The achieved results manifest that the size of carbon-based materials and their functional groups are the crucial factors influencing their biocompatibility ${ }^{9,10}$. Moreover, $\mathrm{CuCo}_{2} \mathrm{~S}_{4}, \mathrm{PAN}$, and carbon-based materials have illustrated the widespread biomedical applications and proper biocompatibility ${ }^{11-16}$. Noticeably, combating bacterial contamination using nanostructures as the hotspot has attracted widespread interest all over the globe. Interestingly, the antibacterial activities of the nanostructures containing $\mathrm{Cu}, \mathrm{Co}$, and $\mathrm{S}$ elements as well as carbon-based structures have been enormously investigated ${ }^{17-21}$. It is well known that the permeability and permittivity of structures are the crucial factors bringing microwave

${ }^{1}$ Laser and Plasma Research Institute, Shahid Beheshti University, Tehran 1983969411, Iran. ${ }^{2}$ Department of Chemical Engineering, Energy Institute of Higher Education, Saveh, Iran. ${ }^{\bowtie}$ email: reza_peymanfar@ alumni.iust.ac.ir; h-tavassoli@sbu.ac.ir 
absorption, given by the transmission line theory. The dielectric feature, conductive loss, and electron hopping pave the way for the permittivity of absorbers. The chemical functional groups, crystal dislocations, and defects alongside the morphology play key roles in promoting the dielectric characteristics ${ }^{22-29}$. Over the past decades, biomass-derived materials due to renewable, eco-friendly, and abundant resources have attracted a great deal of attention as ideal candidates in energy production, conversion, and storage as well as supercapacitors, $\mathrm{CO}_{2}$ capture, biogas production, and so on ${ }^{30-33}$. Noteworthy, biomass-derived materials have emerged as light-weight, low-cost, and green microwave absorbers, which their fascinating microwave characteristics are originated from their dielectric and conductive properties ${ }^{29,34}$. Nowadays, apart from carbon-based structures, various structures including transition metal carbides and nitrides (MXenes), metal-organic framework (MOF)-derived materials, nanostructured metals and oxides, as well as other conductive polymers comprising polyaniline, polypyrrole, polythiophene, and polydopamine were enormously used as microwave absorbing materials ${ }^{35-44}$. It should be noted that the cobalt-based spinel oxides have exhibited salient microwave absorbing features meanwhile the sulfide nanostructures have recently intrigued a great deal of interest due to their considerable relaxation loss features, generated by their narrow energy band gaps ${ }^{45-47}$. Among them, $\mathrm{CuS}, \mathrm{FeS}_{2}, \mathrm{MoS}_{2}$, and $\mathrm{WS}_{2}$ as sulfide nanostructures as well as waxberry, eggshell membrane, wood-based, chicken featherfibers, fish skin, rice, and corn stover as biomass materials were applied to fabricate the microwave absorbing materials ${ }^{27,48-56}$. Light-weight and low-cost electromagnetic wave absorbers with high performances based on biomass-derived reduced graphene oxides ( $\mathrm{rGO}$ ) were reported by Cao et al. The results suggest that biomass-rGO show a maximum RL of $51.7 \mathrm{~dB}$ and an efficient bandwidth of $13.5 \mathrm{GHz}(4.5-18 \mathrm{GHz})$ at a thickness of $3.25 \mathrm{~mm}$, implying the unique critical role of the microstructure in adjusting the electromagnetic microwave absorption performance ${ }^{55}$. Li et al. have investigated the microwave absorbing properties of porous $\mathrm{C} @ \mathrm{CoFe}_{2} \mathrm{O}_{4}$ nanocomposites, derived from the eggshell membrane. The hierarchically porous structures, obtained from the eggshell membrane, and the anchored $\mathrm{CoFe}_{2} \mathrm{O}_{4}$ nanoparticles helped that $\mathrm{C} / \mathrm{CoFe}_{2} \mathrm{O}_{4}$ nanocomposites perform a favorable electromagnetic absorption capability. The porous $\mathrm{C} @ \mathrm{CoFe}_{2} \mathrm{O}_{4}$ nanocomposites achieved the maximum $\mathrm{RL}$ of $49.6 \mathrm{~dB}$ at $9.2 \mathrm{GHz}$ with $30 \%$ loading in the paraffin matrix ${ }^{51}$. $\mathrm{MoS}_{2}$ nanosheets were prepared at $180^{\circ} \mathrm{C}$ by Ji et al. reaching as high as $47.8 \mathrm{~dB}$ at $12.8 \mathrm{GHz}$ due to their high electrical conductivity and the polarization effect. It can also be found that $\mathrm{MoS}_{2}$ exhibited an efficient electromagnetic wave absorption bandwidth of $5.2 \mathrm{GHz}(\mathrm{RL}>10 \mathrm{~dB})$ at thicknesses of 1.9 and $2.0 \mathrm{~mm}^{57}$. Kar et al. have architected lightweight, nature-friendly, and low-cost microwave absorbing materials by pyrolyzing the chicken featherfibers at diverse temperatures. The sample pyrolyzed at $1400{ }^{\circ} \mathrm{C}$ attained a maximum RL of $44.6 \mathrm{~dB}$ and broad efficient bandwidth sharing $52.9 \%$ of the entire $\mathrm{x}$-band frequencies with a thickness of $1.68 \mathrm{~mm}$. The achieved results testified that the dipole, defect, and interfacial polarization, as well as impedance matching, multiple reflections, and multiple scattering, are the vital parameters bringing the microwave features ${ }^{56}$. Recently, the size and medium influence on the microwave absorbing, electromagnetic shielding, optical, and magnetic properties of $\mathrm{CuCo}_{2} \mathrm{~S}_{4}$ nanostructures were assessed ${ }^{58}$. Diverse morphologies of carbon-based structures including grapheme, flake, sphere, nanotube, fiber, graphene foam, and carbide were applied as microwave absorbing structures ${ }^{59-64}$. In this study, pure and uniform CMTs were prepared by pyrolyzing a biowaste (Populus euphratica harvest) as novel raw material and functionalized by an innovative complementary method. Interestingly, carrollite as a novel spinel sulfide microwave absorber was architected and anchored onto FCMT as well as its synergic effects in FCMT/carrollite composite were scrupulously dissected. It is noteworthy that the antibacterial characteristic of the nanocomposites as well as the used PAN as an absorbing medium, improving mechanical properties compared to the conventional wax, develop the practical applications of the tailored composites.

\section{Materials and methods}

Materials. Cobalt (II) nitrate hexahydrate, copper (II) acetate monohydrate, N, N-dimethylformamide (DMF), ethanol, and nitric acid (65\%) were purchased from Merck. Moreover, sodium sulfide hydrate (60.062.0\%) was obtained from Samchun Chemicals while PAN was supplied from Sigma-Aldrich. Mueller-Hinton agar was purchased from the IBRESCO meanwhile E. coli ATCC 25922 and S. aureus ATCC 25923 obtained from Darvash Co. were employed to investigate the antibacterial characteristics.

Experimental steps. Preparation of FCMTs by biomass. CMTs were fabricated by pyrolyzing the harvest of Populus euphratica at $500^{\circ} \mathrm{C}$ in an $\mathrm{N}_{2}$ environment for $3 \mathrm{~h}$. The prepared CMTs were functionalized by a novel modified complementary method. Initially, $0.13 \mathrm{~g}$ of CMTs was suspended in $15 \mathrm{ml}$ nitric acid using simultaneously an overhead stirrer and ultrasonic bath for $2 \mathrm{~h}$. Subsequently, the oxygen-containing functional groups fully anchored onto CMTs by a solvothermal process for $2 \mathrm{~h}$ at $120^{\circ} \mathrm{C}$. The obtained FCMTs were rinsed by deionized water to natural $\mathrm{pH}$ and then were dried at $60^{\circ} \mathrm{C}$. The etching treatments performed by sonochemistry elevate defects at grain boundaries while the functionalizing process was fully done through the solvothermal route. The established defects and functional groups generate the diverse polarization relaxation times, ascending the relaxation loss. More significantly, inserting the oxygen-containing functional groups transfer the $\mathrm{sp}^{2}$ hybridization of conjugated CMTs to $\mathrm{sp}^{3}$ hybridization, enhancing polarizability.

Architecting $\mathrm{FCMT/CuCo} \mathrm{S}_{4}$ nanocomposite. Firstly, the copper and cobalt salts in stoichiometric amounts were dissolved in a mixture of deionized water/ethanol $=50 \%(\mathrm{v} / \mathrm{v})$ and then FCMTs by $10 \mathrm{Wt}$. \% were dispersed in the solution by an ultrasonic bath and overhead stirrer, simultaneously. Afterward, the sodium sulfide in a molar ratio of $\mathrm{S}^{2-} / \mathrm{Cu}^{2+}=6$ was separately dissolved in the solvent and added to the aforementioned solution, following that the suspension was treated for $1 \mathrm{~h}$. Next, it was transferred into a p-polyphenylene lined stainless steel autoclave and annealed for $8 \mathrm{~h}$ at $200{ }^{\circ} \mathrm{C}$. The architected nanocomposite was rinsed several times and 

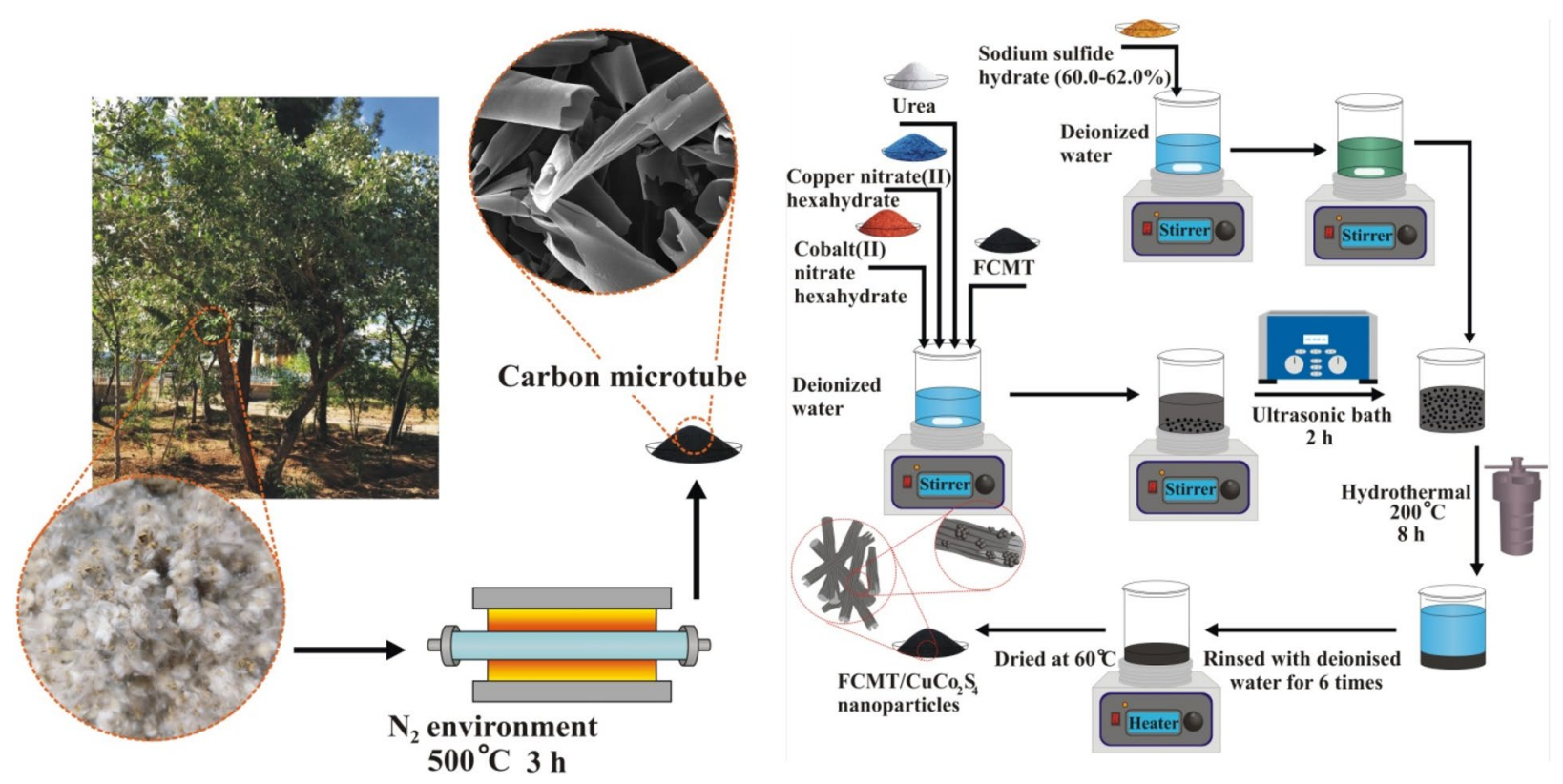

Figure 1. Synthetic route of $\mathrm{FCMT} / \mathrm{CuCo}_{2} \mathrm{~S}_{4}$ nanocomposite.

dried at $60{ }^{\circ} \mathrm{C}$. Eventually, $\mathrm{CuCo}_{2} \mathrm{~S}_{4}$ nanoparticles were prepared based on the presented route in the absence of FCMTs. The fabrication procedures of FCMT/CuCo${ }_{2} \mathrm{~S}_{4}$ nanocomposite have been illustrated in Fig. 1.

Preparation of microwave absorbing and antibacterial samples. The microwave absorbing and antibacterial samples were fabricated through a blending process as follows: PAN was dissolved in DMF and then each sample was blended and sonicated there for $30 \mathrm{~min}$. Subsequently, the suspension was molded at $165^{\circ} \mathrm{C}$ in the rectangular shapes to measure their microwave features. The filler ratio of $\mathrm{CuCo}_{2} \mathrm{~S}_{4}$ and $\mathrm{FCMT} / \mathrm{CuCo} \mathrm{S}_{4}$ nanostructures was guest/guest + host $=50 \mathrm{Wt}$. $\%$ meanwhile it was $5 \mathrm{Wt}$. $\%$ for FCMTs. The chosen amount of FCMTs is in accordance with its ratio in $\mathrm{FCMT} / \mathrm{CuCo}_{2} \mathrm{~S}_{4} / \mathrm{PAN}$ nanocomposite.

Antibacterial assay. A $0.5 \mathrm{McFarland}$ suspension of E. coli and S. aureus bacteria was spread on an agar culture medium. Then, sterile paper discs ( $5 \mathrm{~mm}$ in diameter) were separately soaked in the saturated solutions of DMF and molded PAN, FCMT/PAN, $\mathrm{CuCo}_{2} \mathrm{~S}_{4} / \mathrm{PAN}$, or FCMT/CuCo $\mathrm{S}_{4} / \mathrm{PAN}$, following that the soaked discs were placed on the culture media and incubated at $37^{\circ} \mathrm{C}$ for $24 \mathrm{~h}$ to evaluate the antibacterial features of the samples.

Characterization. The chemical species and crystal phases were revealed by Shimadzu 8400 and D8 advance X-ray diffractometer from Bruker, respectively. The optical performance was studied using Shimadzu MPC-2200 while FESEM and TEM images were obtained by Tescan Mira3 and Phillips instruments. IRI Kashan VSM assessed hysteresis loops of the prepared structures, employed at room temperature. The microwave features were provided by an Agilent technology (E8364A).

FTIR and XRD. FTIR spectra and XRD patterns of FCMT, $\mathrm{CuCo}_{2} \mathrm{~S}_{4}$, and $\mathrm{FCMT} / \mathrm{CuCo}_{2} \mathrm{~S}_{4}$ structures have been depicted in Fig. 2. For FCMT spectrum, the assigned peaks at 661 and $1152 \mathrm{~cm}^{-1}$ are related to the deformation vibrations of $\mathrm{C}-\mathrm{H}$ and stretching vibrations of $\mathrm{C}-\mathrm{O}$ while the observed peak at $1733 \mathrm{~cm}^{-1}$ is attributed to the stretching vibrations of $\mathrm{C}=\mathrm{O}$ functional groups. The shallow band around $3300 \mathrm{~cm}^{-1}$ as well as the absorption bands at 1398,1537 , and $1620 \mathrm{~cm}^{-1}$ are ascribed to the stretching vibrations of hydroxyl, in-plane and out-of-plane bending vibrations of $\mathrm{O}-\mathrm{H}$, as well as symmetric and asymmetric stretching vibrations of $\mathrm{C}=\mathrm{C}$ in conjugated FCMTs, respectively. Noteworthy, it can be seen that the novel modified method loaded the oxygencontaining functional groups onto CMTs while the chemical structure of CMTs was maintained. For $\mathrm{CuCo}_{2} \mathrm{~S}_{4}$ nanoparticles, the shoulder at $604 \mathrm{~cm}^{-1}$ refers to the symmetric and asymmetric stretching vibrations of $\mathrm{Cu}-\mathrm{S}$ and Co-S in the diverse coordinate states ${ }^{50,65-68}$. The notches at $800,869,1102$, and $1383 \mathrm{~cm}^{-1}$ attest to the existing sulphonate, sulfoxide, and sulfones in grain boundaries ${ }^{65,66,69}$. It is found that the water was adsorbed at heterogeneous interfaces of the nanoparticles, suggested by the bumps around 1620 and $3300 \mathrm{~cm}^{-1}$. The observed parallel and overlapped peaks in the spectrum of nanocomposite imply the synthesis of both structures together.

Evidently, the achieved peaks at $2 \theta=25.76^{\circ}, 30.21^{\circ}, 36.58^{\circ}, 45.35^{\circ}, 48.31^{\circ}, 52.98^{\circ}, 60.16^{\circ}, 62.66^{\circ}, 66.99^{\circ}$, $76.10^{\circ}, 80.43^{\circ}$ are in accordance with the (022), (113), (004), (224), (115), (044), (026), (335), (444), (137), (008) Brag reflections (JCPDS: [00-042-1450]) demonstrating that carrollite has been synthesized with cubic crystal system in the absence and presence of FCMTs. It can be seen that FCMTs have an amorphous crystal structure, the peak at $2 \theta=27.43^{\circ}$ (d-spacing $=3.25 \AA$ ) corresponds to the $(002)$ crystal plane indexed to the natural graphite 

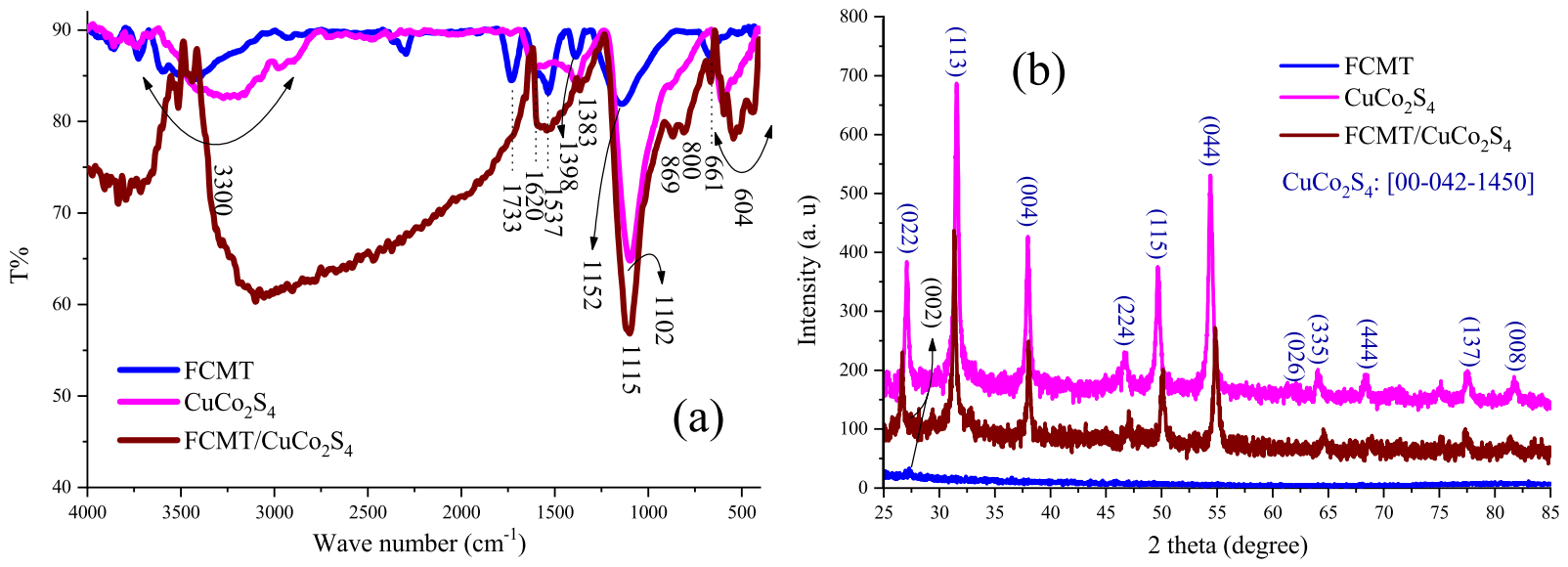

Figure 2. FTIR spectra (a) and XRD patterns (b) of FCMT, $\mathrm{CuCo}_{2} \mathrm{~S}_{4}$, and FCMT/CuCo $\mathrm{S}_{4}$ structures.

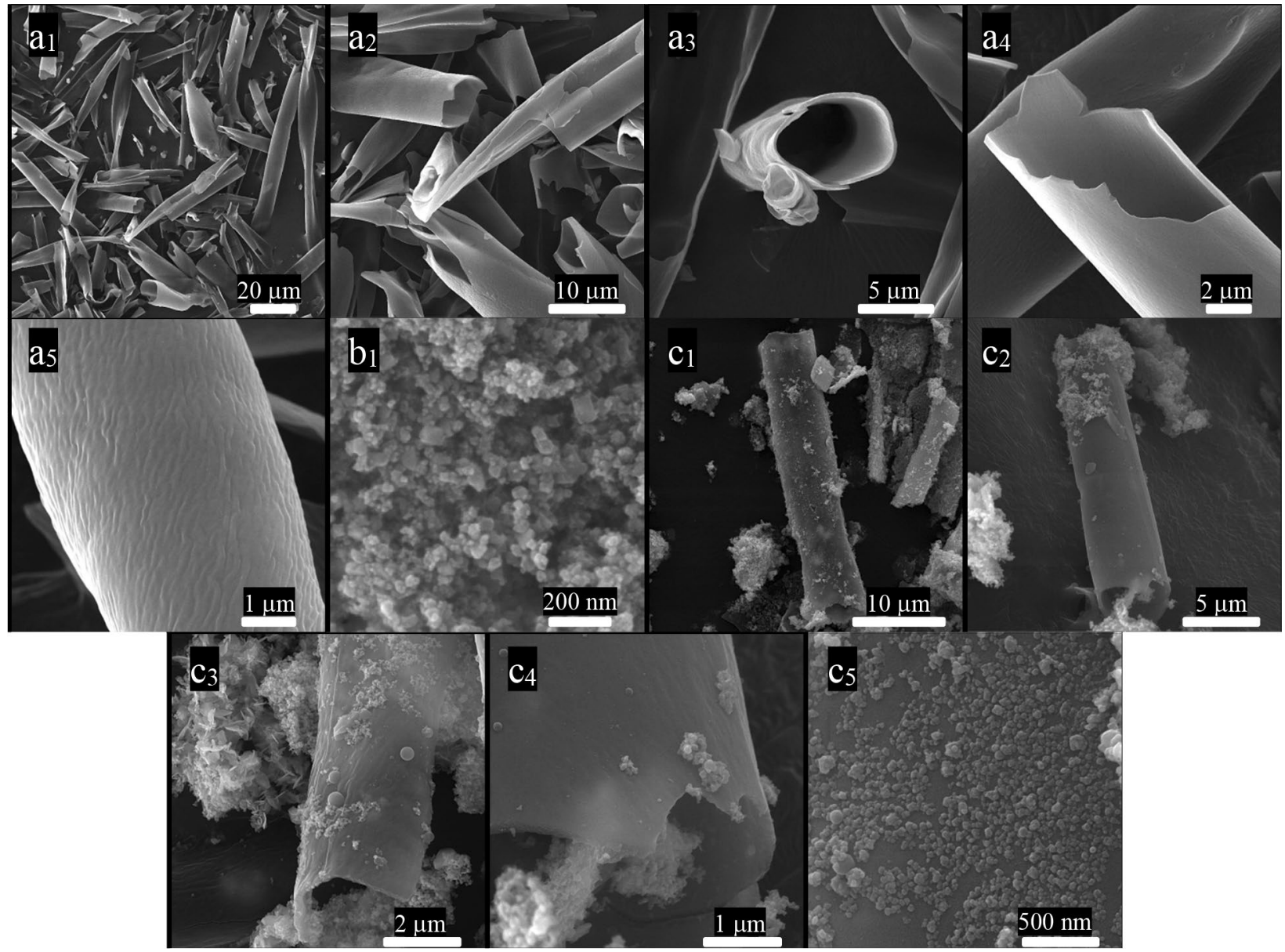

Figure 3. FE-SEM micrographs of FCMT $\left(\mathbf{a}_{1-5}\right), \mathrm{CuCo}_{2} \mathrm{~S}_{4}\left(\mathbf{b}_{\mathbf{1}}\right)$, and FCMT/CuCo $\mathrm{S}_{4}\left(\mathbf{c}_{\mathbf{1 - 5}}\right)$ structures.

structure ${ }^{70-72}$. Crystallite size of $\mathrm{CuCo}_{2} \mathrm{~S}_{4}$ nanoparticles was $32.7 \mathrm{~nm}$ meanwhile it was $35.0 \mathrm{~nm}$ in the nanocomposite, given by Scherrer equation using (113) Brag reflection.

\section{Results and discussions}

FE-SEM and TEM images. FE-SEM and TEM images of FCMT, $\mathrm{CuCo}_{2} \mathrm{~S}_{4}$, and FCMT/CuCo $\mathrm{S}_{4}$ structures with diverse magnifications have been exposed in Figs. 3 and 4. Obviously, FCMTs derived from the biomass have a length ranging from 15 to $60 \mu \mathrm{m}$ with an average diameter of $5 \mu \mathrm{m}$ and their wall thickness is below $200 \mathrm{~nm}$. As revealed, the morphology of CMTs was maintained after the complementary treatments used to anchoring the functional groups onto CMTs surface. It can be seen that the uniform morphology of $\mathrm{CuCo}_{2} \mathrm{~S}_{4}$ nanoparticles with an average thickness of $25 \mathrm{~nm}$ has been formed. The achieved results manifest that the novel 

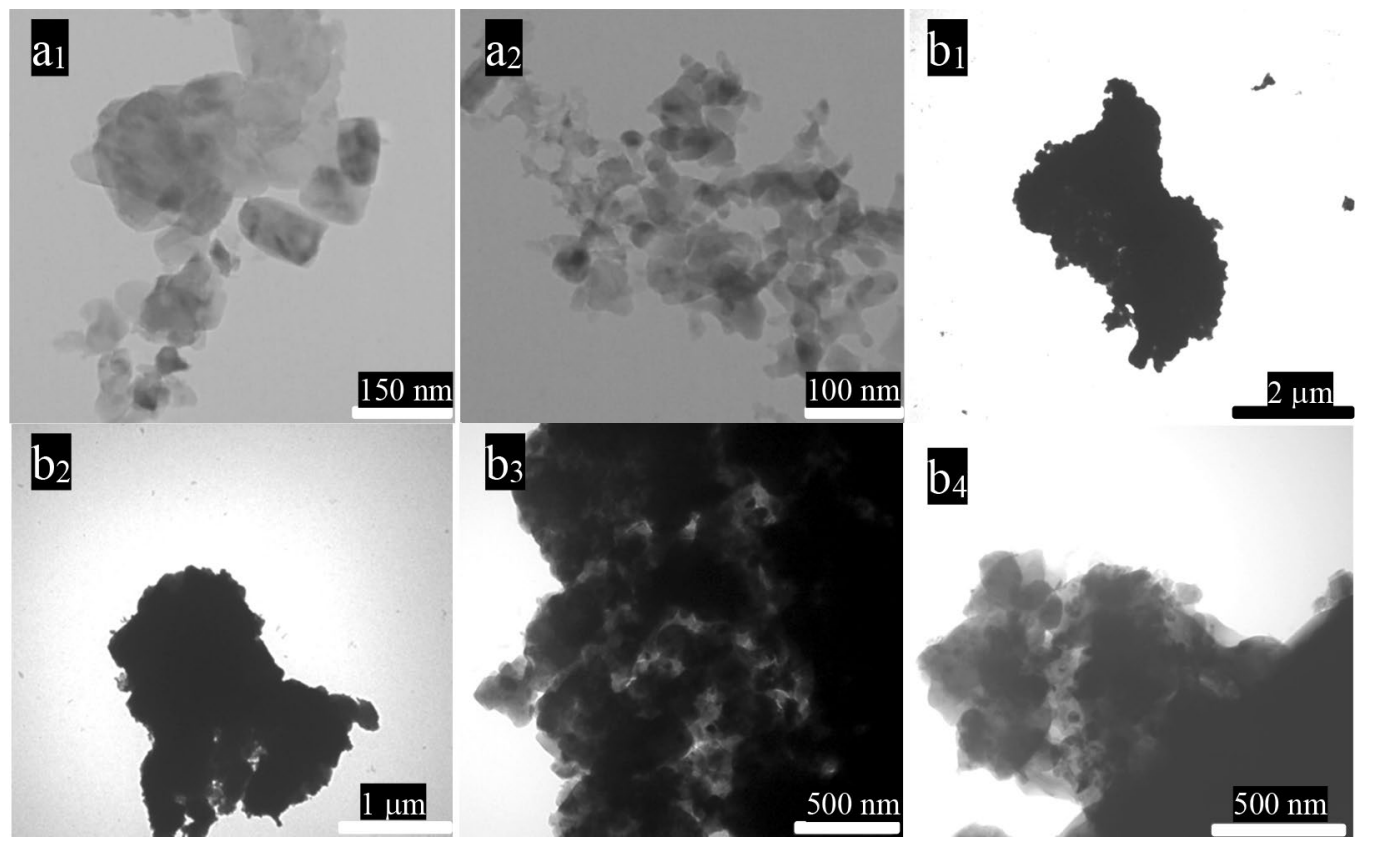

Figure 4. TEM images of $\mathrm{CuCo}_{2} \mathrm{~S}_{4}\left(\mathbf{a}_{1}, \mathbf{a}_{2}\right)$ and $\mathrm{FCMT} / \mathrm{CuCo}_{2} \mathrm{~S}_{4}\left(\mathbf{b}_{1}-\mathbf{b}_{4}\right)$ nanostructures.
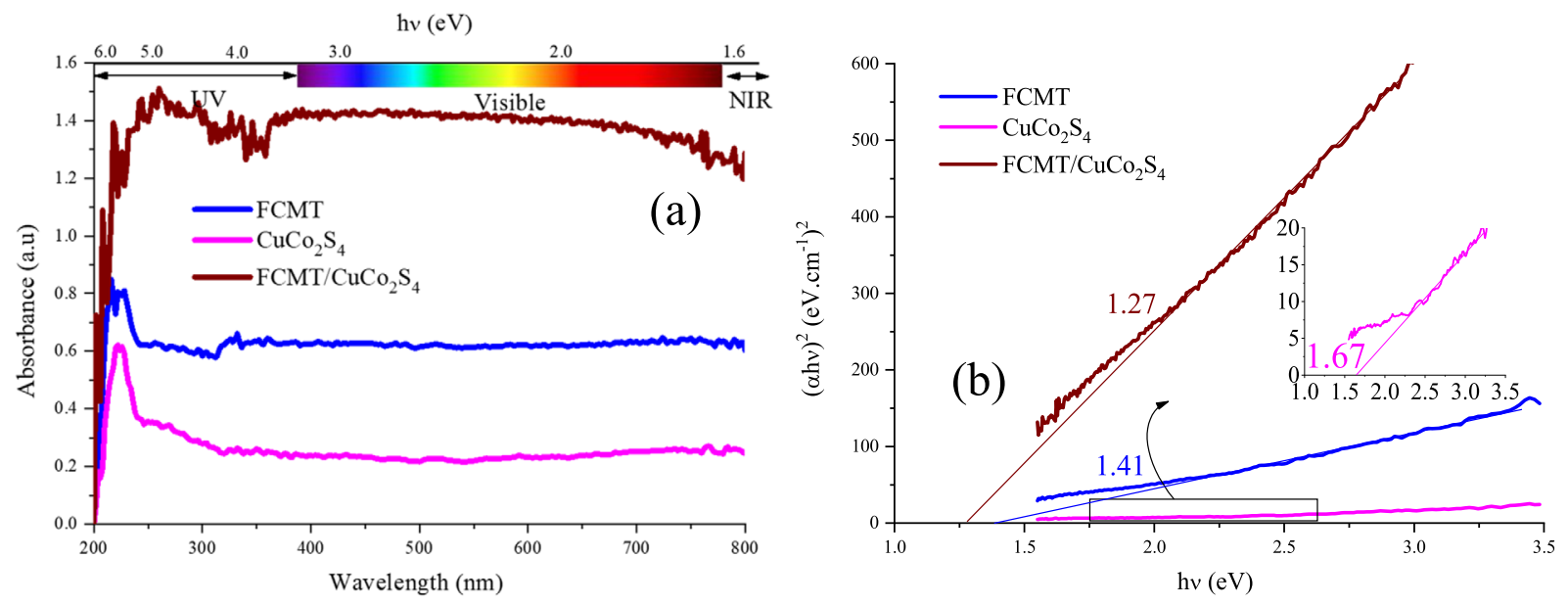

Figure 5. The light absorptions $(\lambda=200-800 \mathrm{~nm})(\mathbf{a})$ and energy band gaps (b) of FCMT, $\mathrm{CuCo}_{2} \mathrm{~S}_{4}$, and FCMT/ $\mathrm{CuCo}_{2} \mathrm{~S}_{4}$ structures.

complementary sonochemistry and solvothermal method, applied to prepare the nanocomposite, placed the nanoparticles onto the surface of FCMTs. Noticeably; the morphology of FCMTs has been maintained after the treatments.

Optical characteristics. Figure 5 exhibits the light absorptions $(\lambda=200-800 \mathrm{~nm})$ and energy band gaps of FCMT, $\mathrm{CuCo}_{2} \mathrm{~S}_{4}$, and FCMT/CuCo $\mathrm{S}_{4}$ structures. The more polarizability is in the clear trade-off with the narrower energy band gap. Particularly, the augmenting polarizability promotes the dielectric loss in microwave absorbers. The energy band gap was defined as the distance between the valence and conduction band. As indicated, the anchoring spinel nanoparticles onto FCMTs led to the red shift of absorption edge. The following equations were used to reveal the energy band gaps: $(\alpha h v)^{2}=h v-E g, \alpha=-1 / t \ln T$, and $T=10^{-\mathrm{A}}$, where $\mathrm{T}, \mathrm{A}, \alpha, v$, $\mathrm{t}, \mathrm{h}$, and $\mathrm{E}_{\mathrm{g}}$ are obtained by the transmittance, absorbance, absorption coefficient, frequency, thickness, Planck constant, and energy gap, given by Kubelka-Munk theory ${ }^{73}$. It is found that the energy band gap was diminished in the nanocomposite, realized by the produced interactions at the interfaces between FCMTs and nanoparticles as well as augmented average size of the nanoparticles reducing the distance between HOMO and LUMO, desirable for Maxwell-wagner effect and microwave attenuating ${ }^{50}$. The achieved results introduce the prepared nanocomposite as a promising photocatalyst. 


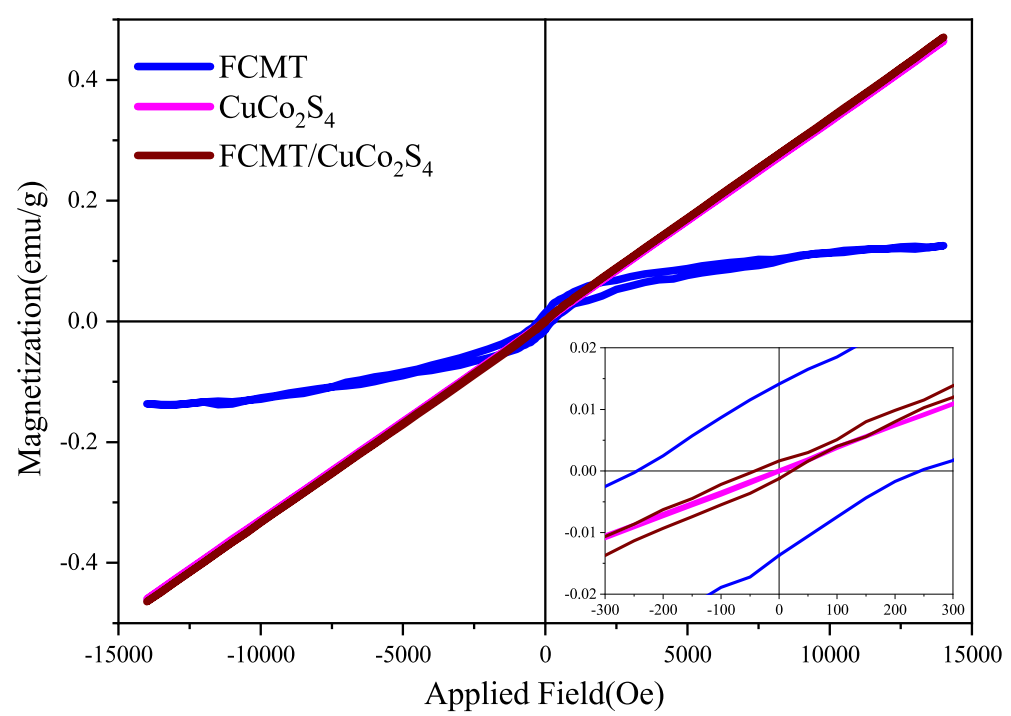

Figure 6. $\mathrm{M}-\mathrm{H}$ loops for $\mathrm{FCMT}, \mathrm{CuCo}_{2} \mathrm{~S}_{4}$, and $\mathrm{FCMT} / \mathrm{CuCo}_{2} \mathrm{~S}_{4}$ structures.

\begin{tabular}{|l|l|l|c|c|c|}
\hline Entry & Sample & $\mathbf{M}(\mathbf{e m u} / \mathbf{g})$ & $\mathbf{M}_{\mathbf{r}}(\mathbf{e m u} / \mathbf{g})$ & $\mathbf{H}_{\mathbf{c}}(\mathbf{O e})$ & Isotropic $\mathbf{M}_{\mathbf{r}} / \mathbf{M}$ \\
\hline 1 & $\mathrm{FCMT}$ & 0.13 & 0.013 & 245.21 & 0.100 \\
\hline 2 & $\mathrm{CuCo}_{2} \mathrm{~S}_{4}$ & 0.46 & $\approx 0.000$ & 3.23 & $\approx 0.000$ \\
\hline 3 & $\mathrm{FCMT} / \mathrm{CuCo}_{2} \mathrm{~S}_{4}$ & 0.47 & 0.002 & 22.09 & 0.004 \\
\hline
\end{tabular}

Table 1. Summarized magnetic characters of FCMT, $\mathrm{CuCo}_{2} \mathrm{~S}_{4}$, and FCMT/CuCo $2 \mathrm{~S}_{4}$ structures.

Magnetic properties. Primitive magnetization versus applied field (M-H) loops for FCMT, $\mathrm{CuCo}_{2} \mathrm{~S}_{4}$, and FCMT/CuCo $\mathrm{S}_{4}$ structures have been illustrated in Fig. 6. It can be seen that the magnetization of $\mathrm{CuCo}_{2} \mathrm{~S}_{4}$ and $\mathrm{FCMT} / \mathrm{CuCo}_{2} \mathrm{~S}_{4}$ nanostructures is augmented by enhancing the applied field. Magnetic parameters including the magnetization at an applied field of $14.5 \mathrm{kOe}(\mathrm{M})$, remanent magnetization $\left(\mathrm{M}_{\mathrm{r}}\right)$, coercivity $\left(\mathrm{H}_{\mathrm{c}}\right)$, and isotropic $M_{r} / M$ were presented in Table 1 . As revealed, $H_{c}$ of the nanocomposite was amplified owing to the spin pinning at heterogeneous interfaces. More interestingly, intermediate structures produced by the oxygencontaining functional groups, anchored onto FCMTs, enhance the size of nanoparticles in the nanocomposite, influencing the magnetic features, defined by Snoek's law ${ }^{74-76}$. The observed ferromagnetic property of FCMTs is ascribed to their unique morphology as well as the produced crystal defects and distortions along the complementary oxidative treatments, hence, the presented factors induce delocalize electronic structures and develop localize dipole moments ${ }^{77-80}$. Natural resonance equation states that the isotropic magnetic exchange interactions and magnetization are the vital keys tuning the microwave absorbing bandwidth ${ }^{81-84}$.

Antibacterial properties. The agar diffusion method was applied to investigate the antibacterial characteristics of samples. Figure 7 and Table 2 have exposed the antibacterial activity of PAN, FCMT/PAN, $\mathrm{CuCo}_{2} \mathrm{~S}_{4} /$ $\mathrm{PAN}$, and FCMT/CuCo $\mathrm{S}_{4} / \mathrm{PAN}$ against $E$. coli and $S$. aureus. As revealed, PAN and FCMT have not any antibacterial properties against $E$. coli and $S$. aureus. However, the observed inhibition zones are derived from the antibacterial properties of $\mathrm{CuCo}_{2} \mathrm{~S}_{4}$ nanostructures. The antibacterial characteristics of the nanostructures are essentially originated from the established reactive oxygen species (ROS) as well as released metal ions altering the structure of lipids, proteins, peptidoglycan, and DNA of bacteria, eventually destroying them ${ }^{17,20,85-91}$. It can be seen that the antibacterial feature of the nanoparticles has a trade-off between the type of bacteria, associated with their intrinsic structures ${ }^{20,92}$.

Microwave absorbing and shielding characteristics. The microwave absorptions of fabricated samples were evaluated by the transmission line theory ${ }^{93,94}$. Figures 8 and S1 display microwave absorbing properties and simulation of matching thickness for the samples. As revealed, the maximum RL of $\mathrm{CuCo}_{2} \mathrm{~S}_{4} / \mathrm{PAN}$ with a thickness of $1.75 \mathrm{~mm}$ was $61.88 \mathrm{~dB}$ at $11.60 \mathrm{GHz}$, while the architected FCMT/PAN composite gained a broad efficient bandwidth as wide as $7.91 \mathrm{GHz}(\mathrm{RL}>10 \mathrm{~dB})$ and $3.25 \mathrm{GHz}(\mathrm{RL}>20 \mathrm{~dB})$ with a thickness of $2.00 \mathrm{~mm}$. More significantly, FCMT/CuCo $\mathrm{S}_{4} / \mathrm{PAN}$ demonstrated a maximum RL of $56.61 \mathrm{~dB}$ at $12.36 \mathrm{GHz}$ and an efficient bandwidth of $2.04 \mathrm{GHz}(\mathrm{RL}>20 \mathrm{~dB})$ with only $1.75 \mathrm{~mm}$ in thickness. The quarter wavelength mechanism denotes that there is a clear trade-off between the matching frequency and thickness, tuned by the relative complex permeability and permittivity ${ }^{95,96}$. Accordingly, $\mathrm{CuCo}_{2} \mathrm{~S}_{4} / \mathrm{PAN}$ and $\mathrm{FCMT} / \mathrm{CuCo}_{2} \mathrm{~S}_{4} / \mathrm{PAN}$ composites demonstrated the thinner matching thicknesses, compared to FCMT/PAN composite. Figure 9 depicts the matching 


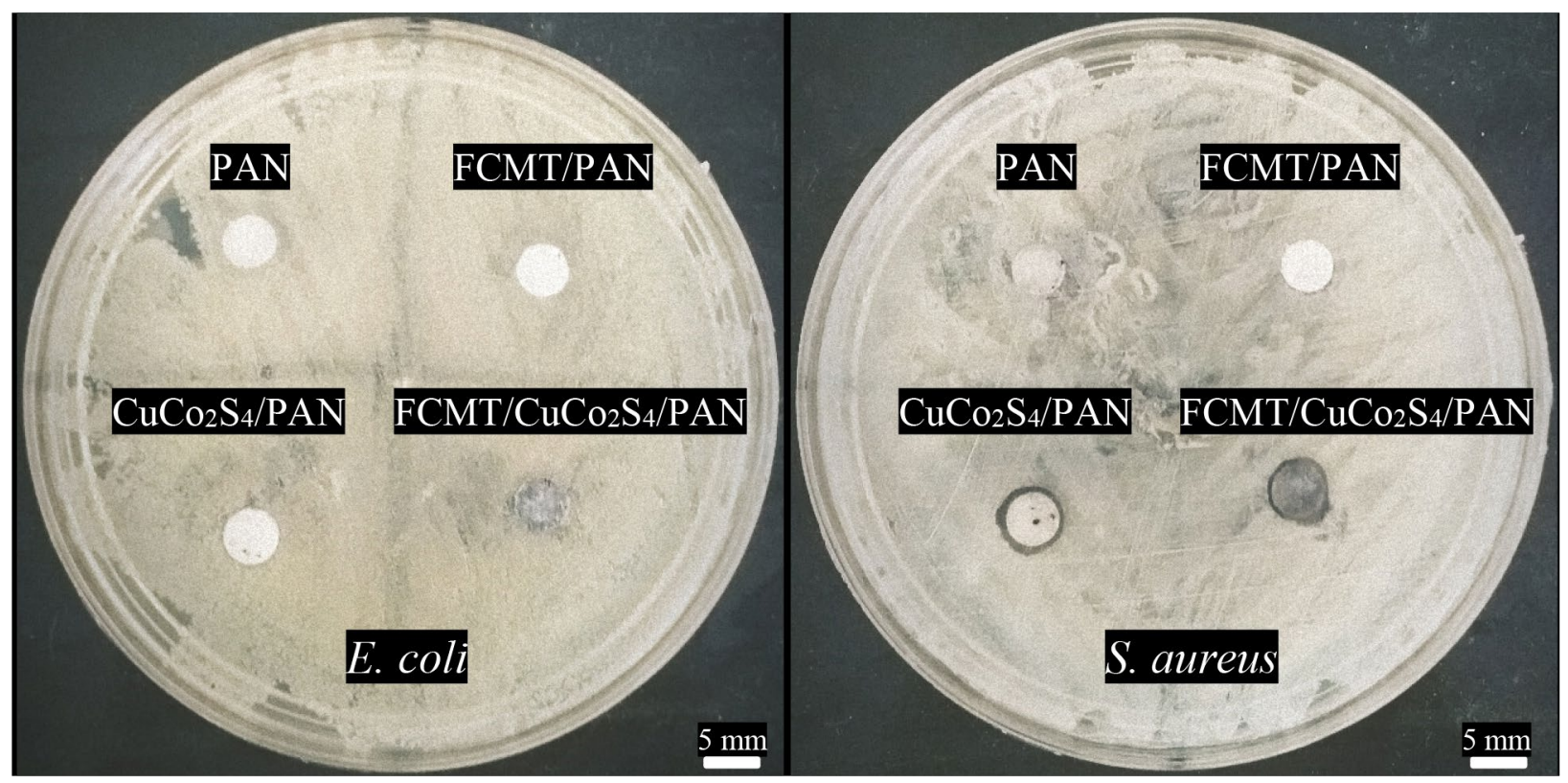

Figure 7. Antibacterial activity of PAN, FCMT/PAN, $\mathrm{CuCo}_{2} \mathrm{~S}_{4} / \mathrm{PAN}$, and $\mathrm{FCMT} / \mathrm{CuCo}_{2} \mathrm{~S}_{4} / \mathrm{PAN}$ against E. coli and S. aureus.

\begin{tabular}{|l|l|l|}
\hline Sample & E. coli zone of inhibition $(\mathbf{m m})$ & S. aureus zone of inhibition $(\mathbf{m m})$ \\
\hline PAN & - & - \\
\hline FCMT/PAN & - & - \\
\hline $\mathrm{CuCo}_{2} \mathrm{~S}_{4} / \mathrm{PAN}$ & - & 6.78 \\
\hline FCMT $/ \mathrm{CuCo}_{2} \mathrm{~S}_{4} / \mathrm{PAN}$ & - & 6.97 \\
\hline
\end{tabular}

Table 2. Inhibition zone diameters of the samples.

thickness versus maximum RL and efficient bandwidth $(\mathrm{RL}>10 \mathrm{~dB})$ of the absorbers, as well as Fig. 10 represents a comparative diagram related to the maximum $\mathrm{RL}$ and efficient bandwidth ( $\mathrm{RL}>10 \mathrm{~dB}$ ) of the reported results and this research ${ }^{51-56,97-101}$.

Frequency dependence of complex permittivity and permeability of the samples has been depicted in Fig. 11. The real part of permittivity is originated from dipole and interfacial polarizations ${ }^{53,54,102}$. It can be seen that FCMTs, ornamented by $\mathrm{CuCo}_{2} \mathrm{~S}_{4}$ nanoparticles, indicated the augmented relaxation loss mechanism due to the intrinsic characteristics of FCMTs, nanoparticles, and PAN, as well as, the emerged exclusive interactions at heterogeneous interfaces. Conductive loss is the key factor, boosting the imaginary part of permittivity ${ }^{53,103}$. As indicated, anchoring the nanoparticles onto FCMTs amplifies the conductive loss mechanism, compared to the FCMT/PAN composite. The observed notches at permeability curves are generated from the natural and exchange resonances ${ }^{82,103}$. It is found that $\mathrm{CuCo}_{2} \mathrm{~S}_{4}$ nanoparticles and $\mathrm{FCMT} / \mathrm{CuCo}_{2} \mathrm{~S}_{4}$ nanocomposite showed the considerable imaginary part of permeability, derived from the intrinsic features of nanoparticles. These phenomena are realized by the produced crystal defects, distortions, and dislocations, as well as the induced magnetic dipole moments, established by the unique interactions at grain boundaries ${ }^{104,105}$. Eddy current loss plays a vital role in microwave absorption. The more constant eddy current curve imply to the more eddy current loss mechanism ${ }^{27}$. Evidently, the mechanism of eddy current loss commands in the absorbing media of FCMT/ $\mathrm{CuCo}_{2} \mathrm{~S}_{4} / \mathrm{PAN}$ and FCMT/PAN composites over $14.50 \mathrm{GHz}$ (Figure S2).

Figure 12 exposes Cole-Cole plot, impedance matching $(Z)$, and attenuation constant $(\alpha)$ of the samples. Cole-Cole plot is produced by drawing $\varepsilon^{\prime}$ versus $\varepsilon^{\prime \prime}$. Each emerged semicircle denotes one relaxation loss procedure, deduced by Debye relaxation theory ${ }^{106}$. As given by the plot, the semicircles exhibited that the relaxation mechanism in the composites are ordered as FCMT/PAN $<\mathrm{CuCo}_{2} \mathrm{~S}_{4} / \mathrm{PAN}<\mathrm{FCMT} / \mathrm{CuCo}_{2} \mathrm{~S}_{4} / \mathrm{PAN}$. Noteworthy, PAN as a novel absorbing matrix develops the dielectric characteristics of samples due to its functional groups. $\mathrm{Z}$ mechanism $(Z=1)$ is in compromise with the propagation of incident waves in the absorbing matrix ${ }^{107-109}$. The achieved results attest that this mechanism is the crucial factor leading to the outstanding microwave attenuation of FCMT/PAN composite. Accordingly, incident waves more influence into the absorbing medium, then absorbing mechanisms such as multiple reflections and scattering as well as the quarter wavelength and canceled waves can be elevated. $\alpha$ and dissipation factor $(\tan \delta$ - Figure S2) estimate the ability of an absorber for energy conversion $^{51,100,110}$. The achieved results manifest that the more $\alpha$ and $|\tan \delta|$ are realized by the more imaginary part of permeability and permittivity. Schematic illustration of the microwave absorbing mechanisms has been shown in Fig. 13. 

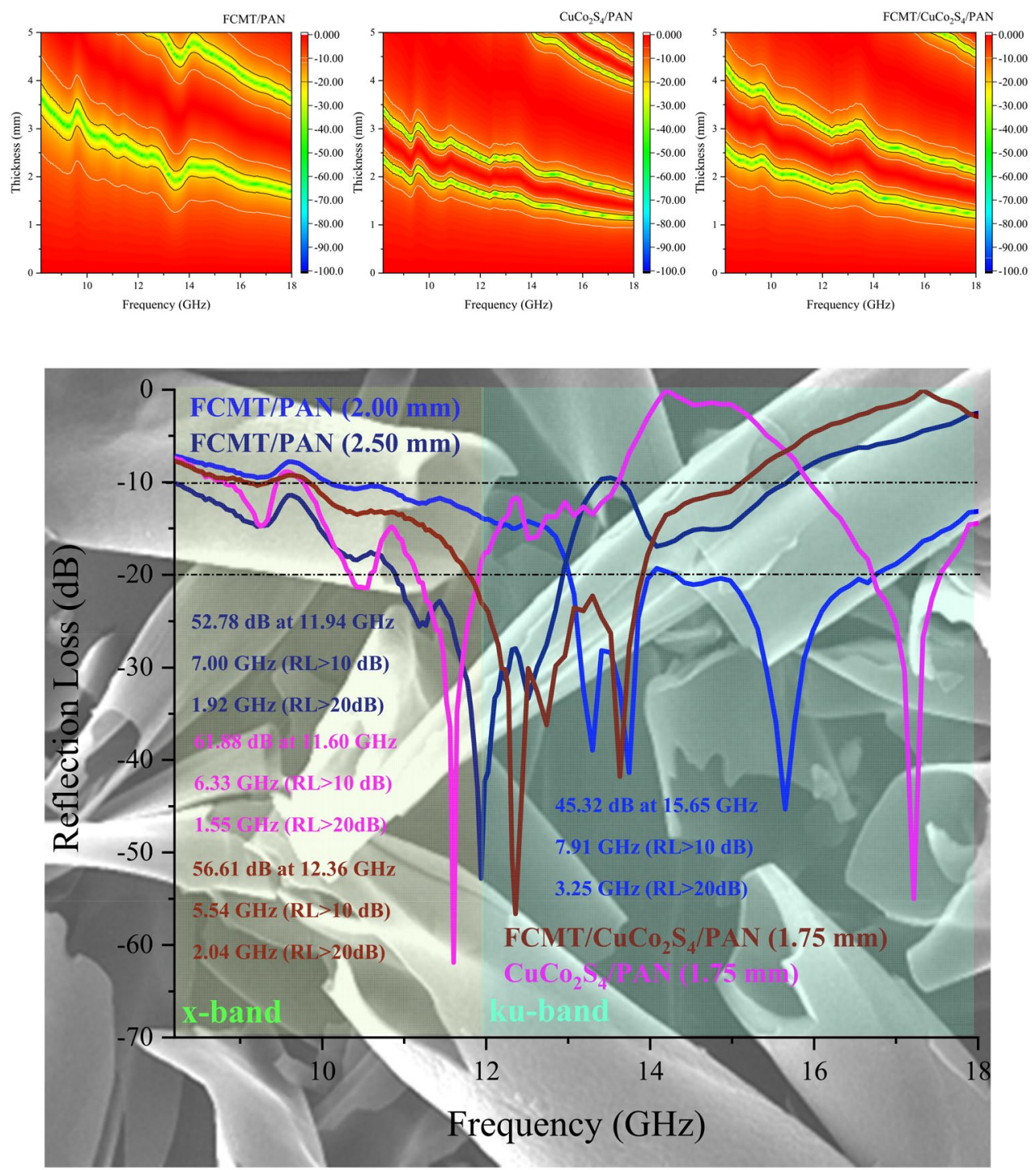

Figure 8. Microwave absorption and efficient bandwidth of the samples at $\mathrm{x}$ and ku-band frequencies.
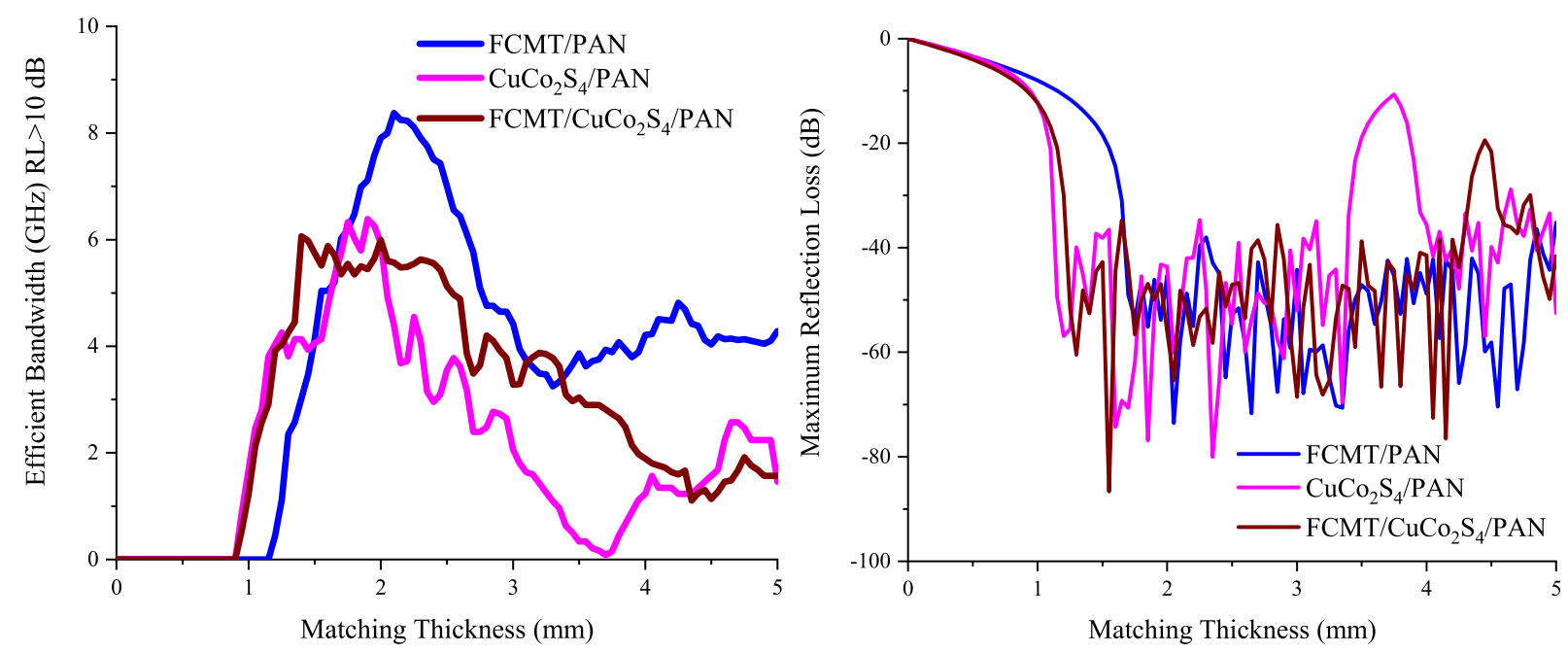

Figure 9. Matching thickness versus maximum RL and efficient bandwidth ( $\mathrm{RL}>10 \mathrm{~dB}$ ) of the absorbers. 


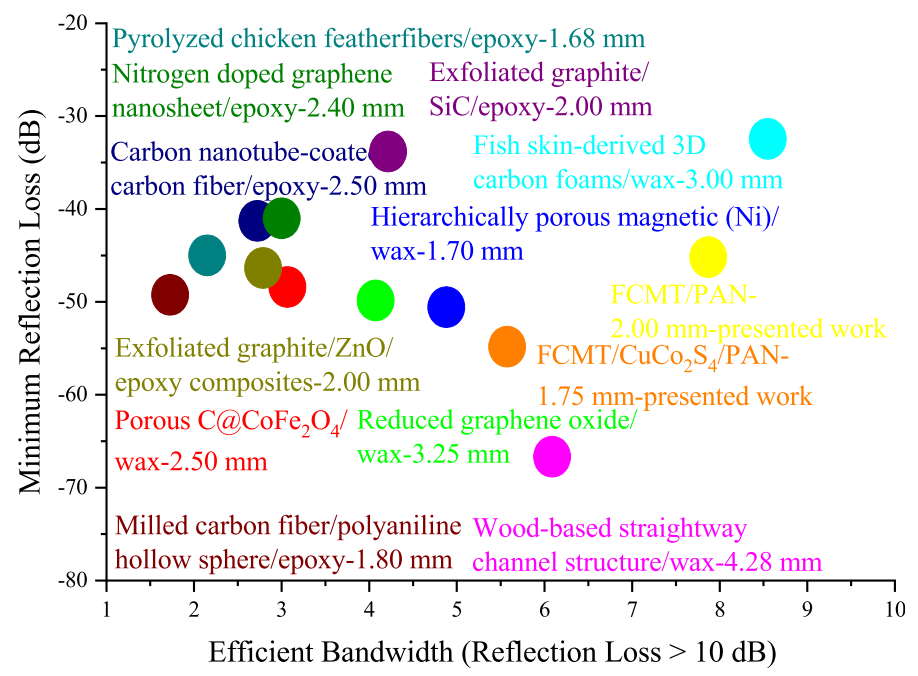

Figure 10. Comparing the microwave absorbing properties of the carbon-based absorbers ${ }^{51-56,97-101}$.
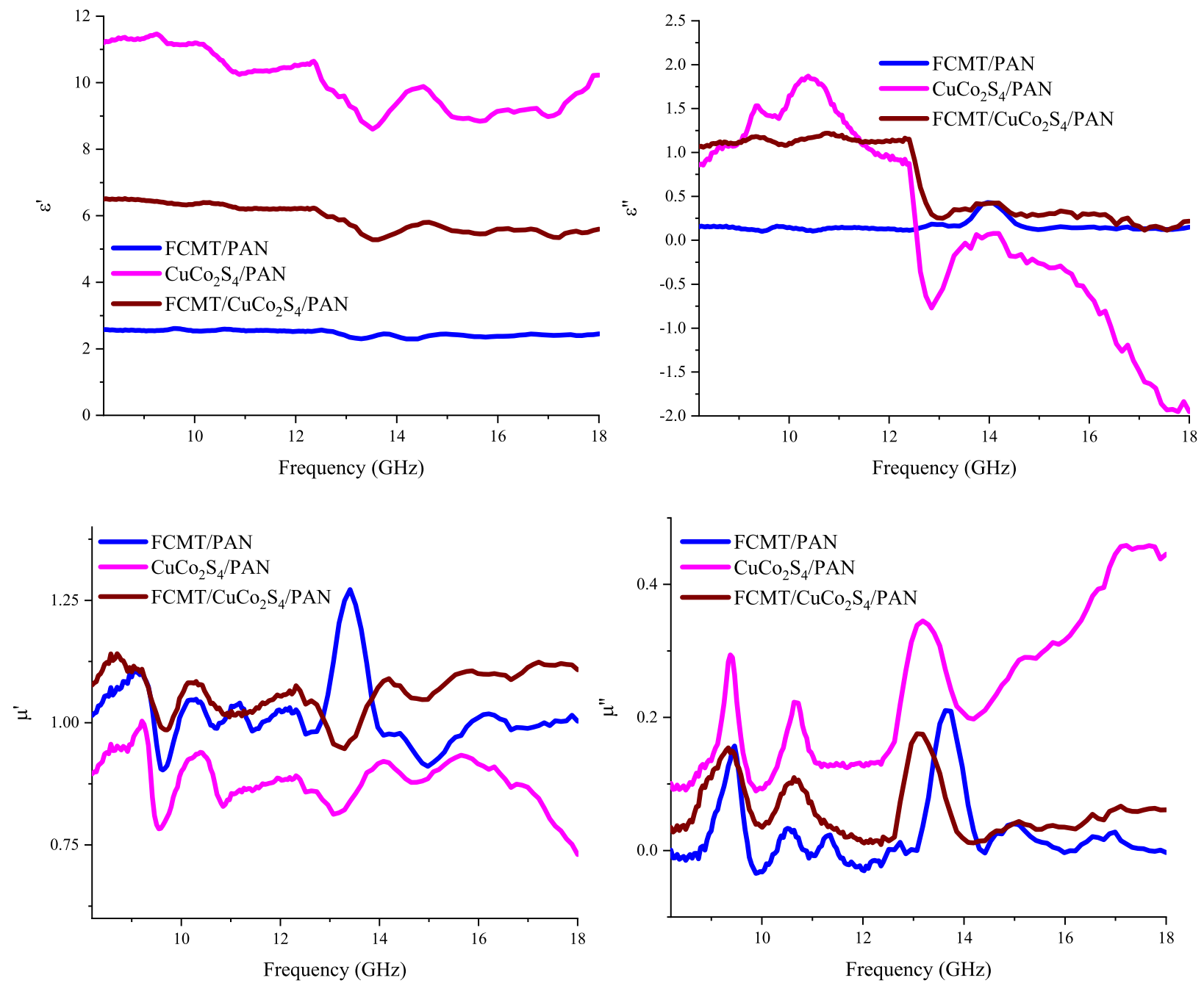

Figure 11. Relative complex permeability and permittivity of the absorbers from 8.2 to $18 \mathrm{GHz}$. 

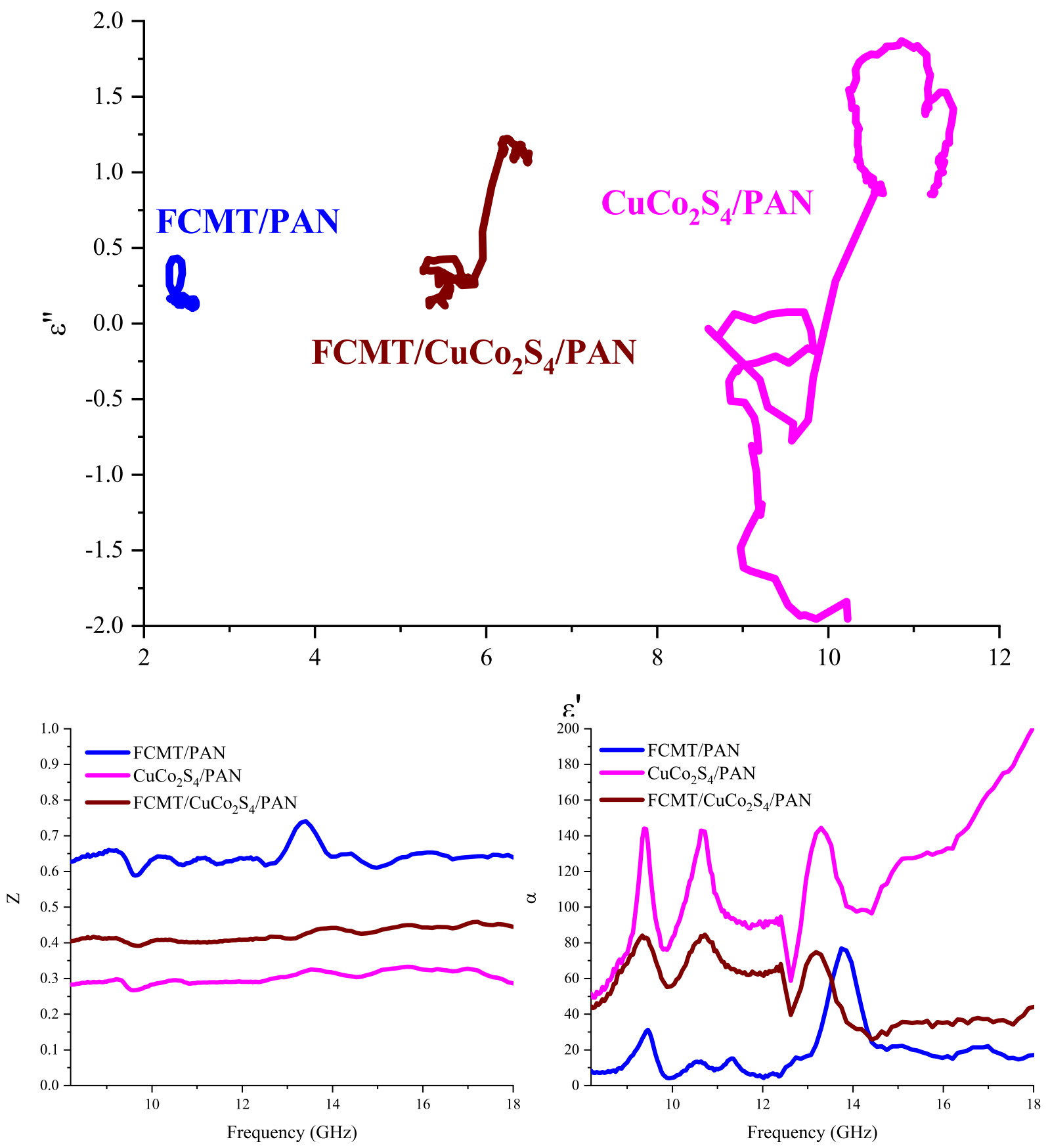

Figure 12. Cole-Cole plot, $\mathrm{Z}$, and $\alpha$ for the tailored structures.

The electromagnetic interference SEs of the samples with $2.00 \mathrm{~mm}$ in thickness were assessed. As known, $\mathrm{SE}_{\mathrm{T}}$ is the sum of SEs attributed to the reflectance $\left(\mathrm{SE}_{\mathrm{R}}\right)$ and absorbance $\left(\mathrm{SE}_{\mathrm{A}}\right)^{111}$. Figures 14 and $\mathrm{S} 3$ exhibit the electromagnetic interference SEs of the samples. Interestingly, FCMT/CuCo $2 \mathrm{~S}_{4} / \mathrm{PAN}$ and $\mathrm{CuCo}_{2} \mathrm{~S}_{4} / \mathrm{PAN}$ nanocomposites demonstrated more than 90 and $97 \% \mathrm{SE}_{\mathrm{T}}$ at entire $\mathrm{x}$ and ku-band frequencies. It should be noted that the eye-catching $\mathrm{SE}_{\mathrm{T}}$ of the samples are derived from the absorbance, generated from the dominant microwave absorbing mechanisms existing in their absorbing medium. The achieved results testified that FCMTs as a novel carbon-based material, derived from biomass material, demonstrated outstanding microwave characteristics meanwhile anchoring the nanoparticles onto their structure promoted microwave absorbing features. More significantly, the tailored composites based on PAN, as a practical absorbing matrix, demonstrated the salient microwave absorbing properties as well as considerable $\mathrm{SE}_{\mathrm{T}}$. The obtained results clarified that the remarkable microwave features of the samples are essentially generated from the dipole, interfacial, and defect polarization, conductive loss, natural and exchange resonance, eddy current loss, multiple reflections and scattering, impedance matching, as well as quarter wavelength mechanism. Applied equations to investigate microwave absorbing and shielding properties of the samples were arranged in Supplementary materials. 


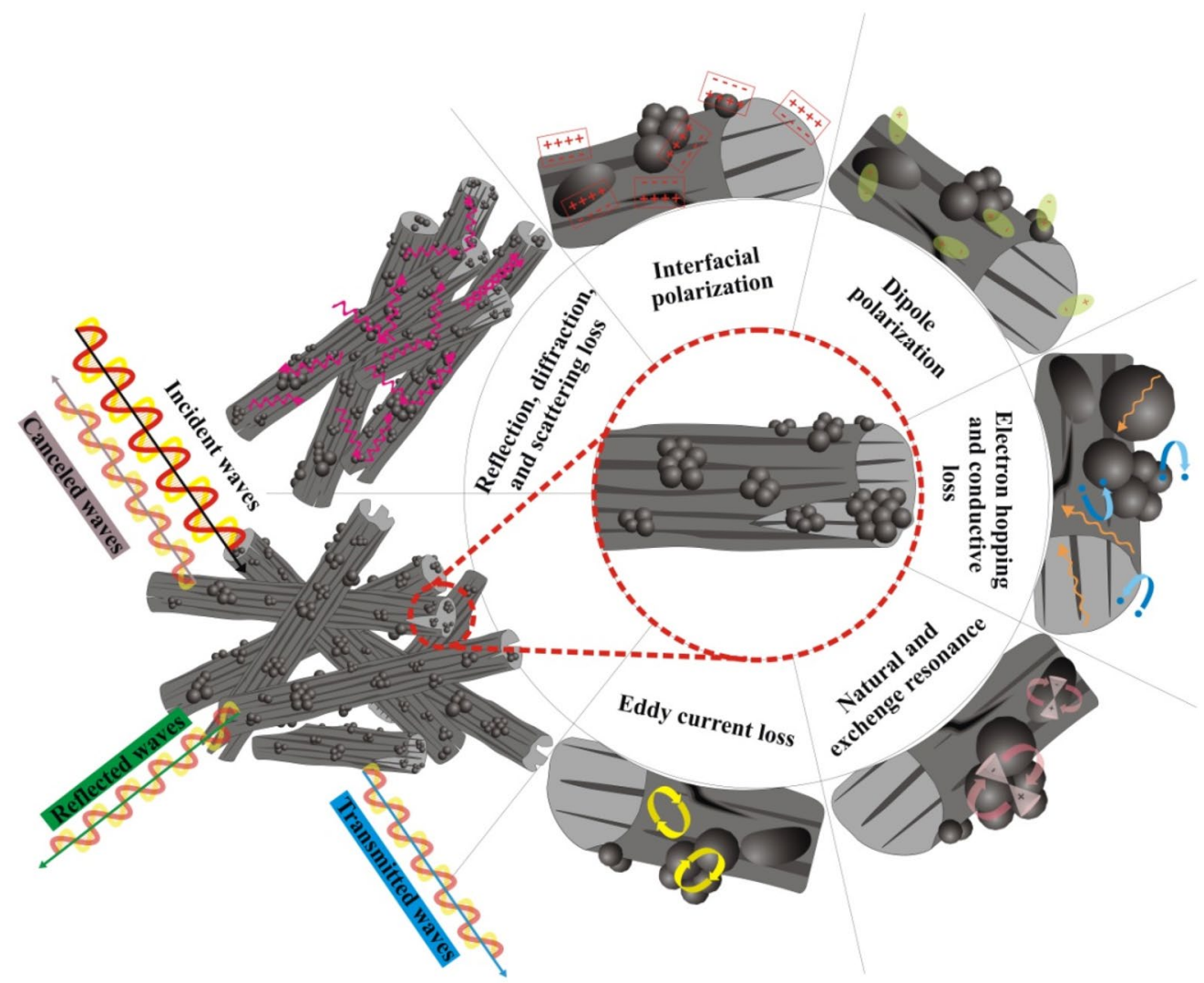

Figure 13. Schematic illustration of the microwave absorbing mechanisms.

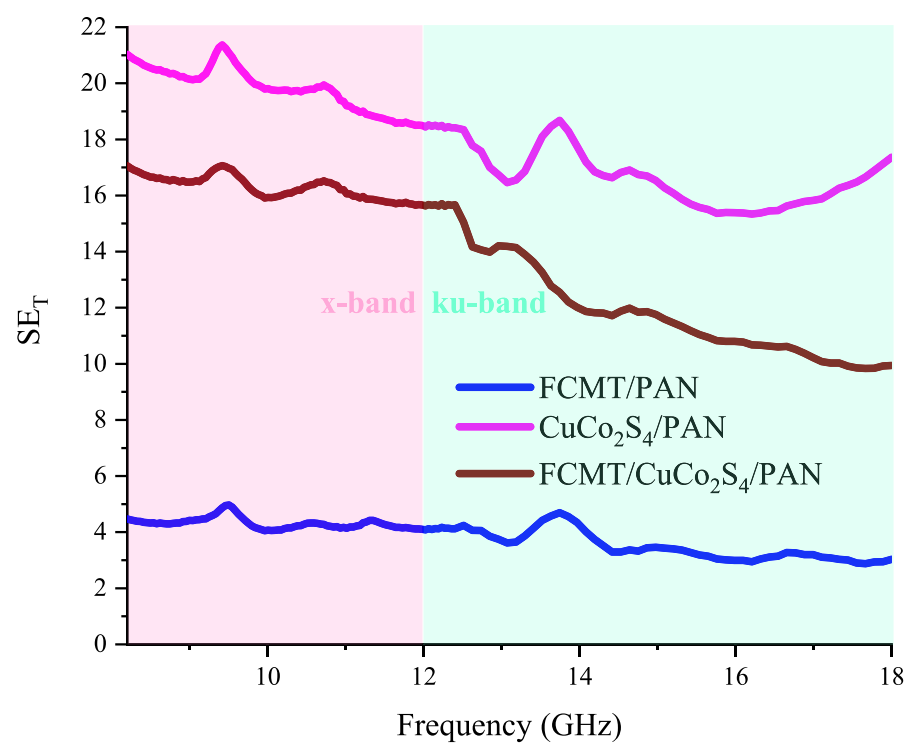

Figure 14. $\mathrm{SE}_{\mathrm{T}}$ of the absorbers at $\mathrm{x}$ and ku-band frequencies.

\section{Conclusion}

In this research, a novel morphology of conjugated carbonaceous structures was fabricated using a novel precursor. The prepared CMTs were functionalized based on the solvothermal and sonochemical routes. Moreover, $\mathrm{CuCo}_{2} \mathrm{~S}_{4}$ nanoparticles were tailored using a solvothermal method and anchored onto FCMTs by an innovative process, as novel microwave absorbing and antibacterial material. All of the analyses revealed that all of the samples were fabricated in good order. Noticeably, PAN was applied as a novel absorbing medium to evaluate 
the microwave absorbing properties of samples, demonstrating the outstanding microwave features. More significantly, microwave absorbing features and electromagnetic interference SEs of the architected samples were scrupulously dissected, illustrating that the relaxation and conductive loss, natural and exchange resonance, as well as quarter wavelength and eddy current loss are the pioneer mechanisms paving the way for the obtained salient microwave characteristics.

Received: 2 February 2021; Accepted: 26 May 2021

Published online: 07 June 2021

\section{References}

1. Vornoli, A., Falcioni, L., Mandrioli, D., Bua, L. \& Belpoggi, F. The contribution of in vivo mammalian studies to the knowledge of adverse effects of radiofrequency radiation on human health. Int. J. Environ. Res. Public Health 16, 3379 (2019).

2. Hao, Y.-H. et al. HIF-1a regulates COXIV subunits, a potential mechanism of self-protective response to microwave induced mitochondrial damages in neurons. Sci. Rep. 8, 1-9 (2018).

3. Garaj-Vrhovac, V., Fučić, A. \& Horvat, D. The correlation between the frequency of micronuclei and specific chromosome aberrations in human lymphocytes exposed to microwave radiation in vitro. Mutat. Res. Lett. 281, 181-186 (1992).

4. Garaj-Vrhovac, V. Micronucleus assay and lymphocyte mitotic activity in risk assessment of occupational exposure to microwave radiation. Chemosphere 39, 2301-2312 (1999).

5. Alkis, M. E. et al. Effect of 900-, 1800-, and 2100-MHz radiofrequency radiation on DNA and oxidative stress in brain. Electromagn. Biol. Med. 38, 32-47 (2019).

6. Zhao, L. et al. Astragaloside protects rat brain from microwave-induced functional injuries via restoring acetylcholine and normalizing electroencephalogram. Environ. Sci. Pollut. Res. 27, 40787-40794 (2020).

7. Verma, S. K. et al. Determining factors for the nano-biocompatibility of cobalt oxide nanoparticles: proximal discrepancy in intrinsic atomic interactions at differential vicinage. Green Chem. 23, 3439-3458. https://doi.org/10.1039/D1GC00571E (2021).

8. Khandual, A. et al. Controlled nano-particle dyeing of cotton can ensure low cytotoxicity risk with multi-functional property enhancement. Mater. Today Chem. 17, 100345 (2020).

9. Grabinski, C., Hussain, S., Lafdi, K., Braydich-Stolle, L. \& Schlager, J. Effect of particle dimension on biocompatibility of carbon nanomaterials. Carbon 45, 2828-2835 (2007).

10. Alavi, M., Jabari, E. \& Jabbari, E. Functionalized carbon-based nanomaterials and quantum dots with antibacterial activity: a review. Expert Rev. Anti Infect. Ther. 19, 35-44 (2021).

11. Huang, X. et al. $\mathrm{CuCo}_{2} \mathrm{~S}_{4}$ nanocrystals: a new platform for multimodal imaging guided photothermal therapy. Nanoscale 9 , 2626-2632 (2017).

12. Zhang, X. et al. $\mathrm{CuCo}_{2} \mathrm{~S}_{4}$ nanocrystals as a nanoplatform for photothermal therapy of arterial inflammation. Nanoscale 11, 9733-9742 (2019).

13. Wu, H.-L. et al. A novel multifunctional biomedical material based on polyacrylonitrile: preparation and characterization. Mater. Sci. Eng. C 62, 702-709 (2016).

14. Wang, Z.-G., Wan, L.-S. \& Xu, Z.-K. Surface engineerings of polyacrylonitrile-based asymmetric membranes towards biomedical applications: an overview. J. Membr. Sci. 304, 8-23 (2007).

15. Cha, C., Shin, S. R., Annabi, N., Dokmeci, M. R. \& Khademhosseini, A. Carbon-based nanomaterials: multifunctional materials for biomedical engineering. ACS Nano 7, 2891-2897 (2013).

16. Ku, S. H., Lee, M. \& Park, C. B. Carbon-based nanomaterials for tissue engineering. Adv. Healthcare Mater. 2, 244-260 (2013).

17. Xin, Q. et al. Antibacterial carbon-based nanomaterials. Adv. Mater. 31, 1804838 (2019)

18. Zheng, Z.-B. et al. Synthesis, photocatalytic, optical, electronic and biological properties of the $\mathrm{CoS}_{2}-\mathrm{CuS}_{\text {on }}$ cellulose nanocomposites as novel nano catalyst by a sonochemical technology. J. Mater. Sci. Mater. Electron. 29, 18531-18539 (2018).

19. Arun, T. et al. Facile synthesized novel hybrid graphene oxide/cobalt ferrite magnetic nanoparticles based surface coating material inhibit bacterial secretion pathway for antibacterial effect. Mater. Sci. Eng. C 104, 109932 (2019).

20. Roy, S. \& Rhim, J.-W. Effect of CuS reinforcement on the mechanical, water vapor barrier, UV-light barrier, and antibacterial properties of alginate-based composite films. Int. J. Biol. Macromol. 164, 37-44 (2020).

21. Vincent, M., Duval, R. E., Hartemann, P. \& Engels-Deutsch, M. Contact killing and antimicrobial properties of copper. J. Appl. Microbiol. 124, 1032-1046 (2018).

22. Cao, M. S. et al. Electronic structure and electromagnetic properties for $2 \mathrm{D}$ electromagnetic functional materials in gigahertz frequency. Ann. Phys. 531, 1800390 (2019).

23. Cao, M. S. et al. Electromagnetic response and energy conversion for functions and devices in low-dimensional materials. Adv. Funct. Mater. 29, 1807398 (2019).

24. Wu, Z. et al. Enhanced microwave absorption performance from magnetic coupling of magnetic nanoparticles suspended within hierarchically tubular composite. Adv. Funct. Mater. 29, 1901448 (2019).

25. He, P. et al. Atomic layer tailoring titanium carbide MXene to tune transport and polarization for utilization of electromagnetic energy beyond solar and chemical energy. ACS Appl. Mater. Interfaces 11, 12535-12543 (2019).

26. Chen, H. et al. Graphene-based materials toward microwave and terahertz absorbing stealth technologies. Adv. Opt. Mater. 7 , 1801318 (2019).

27. Zhang, D. et al. Lightweight and high-performance microwave absorber based on 2D WS 2-RGO heterostructures. Nano Micro Lett. 11, 38 (2019).

28. Li, Q. et al. Toward the application of high frequency electromagnetic wave absorption by carbon nanostructures. Adv. Sci. 6, 1801057 (2019).

29. Zhao, H. et al. Biomass-derived porous carbon-based nanostructures for microwave absorption. Nano Micro Lett. 11, 24 (2019).

30. Yu, F., Li, S., Chen, W., Wu, T. \& Peng, C. Biomass-derived materials for electrochemical energy storage and conversion: overview and perspectives. Energy Environ. Mater. 2, 55-67 (2019).

31. Jin, H. et al. Recent progress in biomass-derived electrode materials for high volumetric performance supercapacitors. Adv. Energy Mater. 8, 1801007 (2018).

32. Singh, G. et al. Biomass derived porous carbon for $\mathrm{CO}_{2}$ capture. Carbon 148, 164-186 (2019).

33. Singh, P. K. et al. Intrinsic molecular insights to enhancement of biogas production from kitchen refuse using alkaline-microwave pretreatment. Sci. Rep. 9, 1-12 (2019).

34. Xu, Z. et al. The preparation of carbonized silk cocoon-Co-graphene composite and its enhanced electromagnetic interference shielding performance. Compos. A Appl. Sci. Manuf. 119, 111-118 (2019).

35. Sankaran, S., Deshmukh, K., Ahamed, M. B. \& Pasha, S. K. Recent advances in electromagnetic interference shielding properties of metal and carbon filler reinforced flexible polymer composites: a review. Compos. A Appl. Sci. Manuf. 114, 49-71 (2018).

36. Zhang, Z. et al. The recent progress of MXene-based microwave absorption materials. Carbon 174, 484-499 (2020). 
37. Wang, Z., Cheng, Z., Fang, C., Hou, X. \& Xie, L. Recent advances in MXenes composites for electromagnetic interference shielding and microwave absorption. Compos. Part A Appl. Sci. Manuf. 136, 105956 (2020).

38. Ma, M. et al. Recent progress of MOF-derived porous carbon materials for microwave absorption. RSC Adv. 11, 16572-16591 (2021).

39. Zhang, Z. et al. A review on metal-organic framework-derived porous carbon-based novel microwave absorption materials. Nano Micro Lett. 13, 1-29 (2021).

40. Wang, M. et al. Construction, mechanism and prospective of conductive polymer composites with multiple interfaces for electromagnetic interference shielding: a review. Carbon 177, 377-402 (2021).

41. Hou, T. et al. A review of metal oxide-related microwave absorbing materials from the dimension and morphology perspective. J. Mater. Sci. Mater. Electron. 30, 10961-10984 (2019).

42. Houbi, A. et al. Microwave absorbing properties of ferrites and their composites: a review. J. Magn. Magn. Mater. 529, 167839 (2021).

43. Maruthi, N., Faisal, M. \& Raghavendra, N. Conducting polymer based composites as efficient EMI shielding materials: a comprehensive review and future prospects. Synth. Met. 272, 116664 (2021).

44. Liu, J., Zhang, L. \& Wu, H. Electromagnetic wave absorbing performance of carbons, carbides, oxides, ferrites and sulfides: review and perspective. J. Phys. D Appl. Phys. 54, 203001 (2021).

45. $\mathrm{Li}$, X. et al. Morphology-controlled synthesis and excellent microwave absorption performance of $\mathrm{ZnCo}_{2} \mathrm{O}_{4}$ nanostructures via a self-assembly process of flake units. Nanoscale 11, 2694-2702 (2019).

46. Qin, M., Lan, D., Wu, G., Qiao, X. \& Wu, H. Sodium citrate assisted hydrothermal synthesis of nickel cobaltate absorbers with tunable morphology and complex dielectric parameters toward efficient electromagnetic wave absorption. Appl. Surf. Sci. 504, $144480(2020)$

47. Wang, J., Wang, B., Feng, A., Jia, Z. \& Wu, G. Design of morphology-controlled and excellent electromagnetic wave absorption performance of sheet-shaped $\mathrm{ZnCo}_{2} \mathrm{O}_{4}$ with a special arrangement. J. Alloys Compd. 834, 155092 (2020).

48. Xing, L. et al. 3D hierarchical local heterojunction of $\mathrm{MoS}_{2} / \mathrm{FeS}_{2}$ for enhanced microwave absorption. Chem. Eng. J. 379, 122241 (2020).

49. Cui, X., Liu, W., Gu, W., Liang, X. \& Ji, G. Two-dimensional $\mathrm{MoS}_{2}$ modified using $\mathrm{CoFe}_{2} \mathrm{O}_{4}$ nanoparticles with enhanced microwave response in the $\mathrm{X}$ and Ku band. Inorg. Chem. Front. 6, 590-597 (2019).

50. Peymanfar, R., Karimi, J. \& Fallahi, R. Novel, promising, and broadband microwave-absorbing nanocomposite based on the graphite-like carbon nitride/CuS. J. Appl. Polym. Sci. 137, 48430 (2019).

51. Huang, L. et al. Microwave absorption enhancement of porous $\mathrm{C} @ \mathrm{CoFe}_{2} \mathrm{O}_{4}$ nanocomposites derived from eggshell membrane. Carbon 143, 507-516 (2019).

52. Xi, J. et al. Wood-based straightway channel structure for high performance microwave absorption. Carbon 124, 492-498 (2017).

53. Zhou, X. et al. Synthesis of fish skin-derived 3D carbon foams with broadened bandwidth and excellent electromagnetic wave absorption performance. Carbon 152, 827-836 (2019).

54. Zhao, H., Cheng, Y., Lv, H., Ji, G. \& Du, Y. A novel hierarchically porous magnetic carbon derived from biomass for strong lightweight microwave absorption. Carbon 142, 245-253 (2019).

55. Zhang, D. et al. Light-weight and low-cost electromagnetic wave absorbers with high performances based on biomass-derived reduced graphene oxides. Nanotechnology 30, 445708 (2019).

56. Singh, S. K., Prakash, H., Akhtar, M. \& Kar, K. K. Lightweight and high-performance microwave absorbing heteroatom-doped carbon derived from chicken feather fibers. ACS Sustain. Chem. Eng. 6, 5381-5393 (2018).

57. Liang, X. et al. A simple hydrothermal process to grow $\mathrm{MoS}_{2}$ nanosheets with excellent dielectric loss and microwave absorption performance. J. Mater. Chem. C 4, 6816-6821 (2016).

58. Peymanfar, R., Ahmadi, A. \& Selseleh-Zakerin, E. Evaluation of the size and medium effects on the microwave absorbing, magnetic, electromagnetic shielding, and optical properties using $\mathrm{CuCo}_{2} \mathrm{~S}_{4}$ nanoparticles. J. Alloys Compd. 848, 156453 (2020).

59. Liang, X. et al. Recent process in the design of carbon-based nanostructures with optimized electromagnetic properties. J. Alloys Compd. 749, 887-899 (2018).

60. Zhang, C. et al. Periodic three-dimensional nitrogen-doped mesoporous carbon spheres embedded with $\mathrm{Co} / \mathrm{Co}_{3} \mathrm{O}_{4}$ nanoparticles toward microwave absorption. ACS Appl. Mater. Interfaces 12, 24102-24111 (2020).

61. Han, C., Zhang, M., Cao, W.-Q. \& Cao, M.-S. Electrospinning and in situ hierarchical thermal treatment to tailor C- $\mathrm{NiCo}_{2} \mathrm{O}_{4}$ nanofibers for tunable microwave absorption. Carbon 171, 953-962 (2021).

62. Wang, X. X., Cao, W. Q., Cao, M. S. \& Yuan, J. Assembling nano-microarchitecture for electromagnetic absorbers and smart devices. Adv. Mater. 32, 2002112 (2020).

63. Zhang, Y., Shen, Y., Dang, M., Zhang, F. \& Du, X. In situ synthesis hydrophobic Co/CoO/C nanofibers with enhanced microwave absorption. Ceram. Int. 47, 9178-9187 (2021).

64. Wu, N. et al. Review on the electromagnetic interference shielding properties of carbon based materials and their novel composites: recent progress, challenges and prospects. Carbon 176, 88-105 (2021).

65. Ge, Y., Wu, J., Xu, X., Ye, M. \& Shen, J. Facile synthesis of $\mathrm{CoNi}_{2} \mathrm{~S}_{4}$ and $\mathrm{CuCo}_{2} \mathrm{~S}_{4}$ with different morphologies as prominent catalysts for hydrogen evolution reaction. Int. J. Hydrog. Energy 41, 19847-19854 (2016).

66. Czioska, S., Wang, J., Teng, X. \& Chen, Z. Hierarchically structured $\mathrm{CuCo}_{2} \mathrm{~S}_{4}$ nanowire arrays as efficient bifunctional electrocatalyst for overall water splitting. ACS Sustain. Chem. Eng. 6, 11877-11883 (2018).

67. Yan, M. et al. Construction of a hierarchical $\mathrm{NiCo}_{2} \mathrm{~S}_{4} @ \mathrm{PPy}$ core-shell heterostructure nanotube array on $\mathrm{Ni}$ foam for a highperformance asymmetric supercapacitor. ACS Appl. Mater. Interfaces 8, 24525-24535 (2016).

68. He, X. et al. High-performance all-solid-state asymmetrical supercapacitors based on petal-like $\mathrm{NiCo}_{2} \mathrm{~S}_{4} /$ polyaniline nanosheets. Chem. Eng. J. 325, 134-143 (2017).

69. Vinayan, B. et al. Performance study of magnesium-sulfur battery using a graphene based sulfur composite cathode electrode and a non-nucleophilic Mg electrolyte. Nanoscale 8, 3296-3306 (2016).

70. Chen, Y., Zhang, A., Ding, L., Liu, Y. \& Lu, H. A three-dimensional absorber hybrid with polar oxygen functional groups of MWNTs/graphene with enhanced microwave absorbing properties. Compos. B Eng. 108, 386-392 (2017).

71. Chen, C.-Y. et al. Remarkable microwave absorption performance of graphene at a very low loading ratio. Compos. B Eng. 114, 395-403 (2017).

72. Liu, J., Wang, Z., Ur Rehman, S. \& Bi, H. Uniform core-shell PPy@carbon microsphere composites with a tunable shell thickness: the synthesis and their excellent microwave absorption performances in the X-band. RSC Adv. 7, 53104-53110 (2017).

73. Kombaiah, K., Vijaya, J. J., Kennedy, L. J. \& Bououdina, M. Optical, magnetic and structural properties of $\mathrm{ZnFe}_{2} \mathrm{O}_{4}$ nanoparticles synthesized by conventional and microwave assisted combustion method: a comparative investigation. Optik Int. J. Light Electron Opt. 129, 57-68 (2017).

74. Acher, O. \& Dubourg, S. Generalization of Snoek's law to ferromagnetic films and composites. Phys. Rev. B 77, 104440 (2008).

75. Song, N.-N. et al. Exceeding natural resonance frequency limit of monodisperse $\mathrm{Fe}_{3} \mathrm{O}_{4}$ nanoparticles via superparamagnetic relaxation. Sci. Rep. 3, 3161 (2013).

76. Snoek, J. Gyromagnetic resonance in ferrites. Nature 160, 90 (1947).

77. Quan, L. et al. The role of graphene oxide precursor morphology in magnetic and microwave absorption properties of nitrogendoped graphene. J. Phys. D Appl. Phys. 52, 305001 (2019). 
78. Gao, C., Xia, B., Gao, D. \& Liu, Y. Structural distortion induced ferromagnetism in two-dimensional metal-free graphitic- $\mathrm{C}_{3} \mathrm{~N}_{4}$ nanosheets. RSC Adv. 9, 21391-21395 (2019).

79. Asih, R. et al. Enhanced magnetism by temperature induced defects in reduced graphene oxide prepared from coconut shells. IEEE Trans. Magn. 54, 1-5 (2018).

80. Tang, N. et al. Spintronic 2D Materials 137-161 (Elsevier, 2020).

81. Qin, F. \& Brosseau, C. A review and analysis of microwave absorption in polymer composites filled with carbonaceous particles. J. Appl. Phys. 111, 4 (2012).

82. Qiao, M. et al. Novel yolk-shell $\mathrm{Fe}_{3} \mathrm{O}_{4} @ v o i d @ S \mathrm{O}_{2} @ P P y$ nanochains toward microwave absorption application. J. Mater. Sci. 56, 1312-1327 (2020).

83. Liu, W. et al. Metal-organic-frameworks derived porous carbon-wrapped Ni composites with optimized impedance matching as excellent lightweight electromagnetic wave absorber. Chem. Eng. J. 313, 734-744 (2017).

84. Gao, S., Zhang, Y., Xing, H. \& Li, H. Controlled reduction synthesis of yolk-shell magnetic@void@C for electromagnetic wave absorption. Chem. Eng. J. 387, 124149 (2020).

85. Palza, H. Antimicrobial polymers with metal nanoparticles. Int. J. Mol. Sci. 16, 2099-2116 (2015).

86. Delgado, K., Quijada, R., Palma, R. \& Palza, H. Polypropylene with embedded copper metal or copper oxide nanoparticles as a novel plastic antimicrobial agent. Lett. Appl. Microbiol. 53, 50-54 (2011).

87. Ahmed, K. B. A. \& Anbazhagan, V. Synthesis of copper sulfide nanoparticles and evaluation of in vitro antibacterial activity and in vivo therapeutic effect in bacteria-infected zebrafish. RSC Adv. 7, 36644-36652 (2017).

88. Mazur, P., Skiba-Kurek, I., Mrowiec, P., Karczewska, E. \& Drożdż, R. Synergistic ROS-associated antimicrobial activity of silver nanoparticles and gentamicin against staphylococcus epidermidis. Int. J. Nanomed. 15, 3551 (2020).

89. Barber, T. L., Aldinger, J., Arnold, J., Leonard, S. \& Ding, M. Copper oxide nanoparticles activate Nrf2, KEAP 1, and downstream target genes in JB6 cells possibly through ROS generation and antioxidant response element (ARE) mechanisms. FASEB J. 34, $1-1(2020)$.

90. Liu, Z. \& Qu, X. New insights into nanomaterials combating bacteria: ROS and beyond. Sci. China Life Sci. 62, 150-152 (2019).

91. Imlay, J. A. Cellular defenses against superoxide and hydrogen peroxide. Annu. Rev. Biochem. 77, 755-776 (2008).

92. Anitha, S., Brabu, B., Thiruvadigal, D. J., Gopalakrishnan, C. \& Natarajan, T. Optical, bactericidal and water repellent properties of electrospun nano-composite membranes of cellulose acetate and ZnO. Carbohydr. Polym. 87, 1065-1072 (2012).

93. Cao, W.-Q., Wang, X.-X., Yuan, J., Wang, W.-Z. \& Cao, M.-S. Temperature dependent microwave absorption of ultrathin graphene composites. J. Mater. Chem. C 3, 10017-10022 (2015).

94. Mustaffa, M. S., Abdullah, N. H., Ismail, I. \& Ibrahim, I. R. An investigation of microstructural, magnetic and microwave absorption properties of multi-walled carbon nanotubes $/ \mathrm{Ni}_{0.5} \mathrm{Zn}_{0.5} \mathrm{Fe}_{2} \mathrm{O}_{4}$. Sci. Rep. 9, 1-7 (2019).

95. Shu, R. et al. Facile preparation and microwave absorption properties of $\mathrm{RGO} / \mathrm{MWCNTs} / \mathrm{ZnFe}_{2} \mathrm{O}_{4}$ hybrid nanocomposites. J. Alloys Compd. 743, 163-174 (2018).

96. Lei, L. et al. Hydrangea-like $\mathrm{Ni} / \mathrm{NiO} / \mathrm{C}$ composites derived from metal-organic frameworks with superior microwave absorption. Carbon 173, 69-79 (2021).

97. Chamoli, P., Singh, S. K., Akhtar, M., Das, M. K. \& Kar, K. K. Nitrogen doped graphene nanosheet-epoxy nanocomposite for excellent microwave absorption. Phys. E. 103, 25-34 (2018).

98. Singh, S. K., Akhtar, M. J. \& Kar, K. K. Synthesis of a lightweight nanocomposite based on polyaniline 3D hollow spheres integrated milled carbon fibers for efficient X-band microwave absorption. Ind. Eng. Chem. Res. 59, 9076-9084 (2020).

99. Baskey, H. B., Singh, S. K., Akhtar, M. J. \& Kar, K. K. Investigation on the dielectric properties of exfoliated graphite-silicon carbide nanocomposites and their absorbing capability for the microwave radiation. IEEE Trans. Nanotechnol. 16, 453-461 (2017).

100. Singh, S. K., Akhtar, M. J. \& Kar, K. K. Hierarchical carbon nanotube-coated carbon fiber: ultra lightweight, thin, and highly efficient microwave absorber. ACS Appl. Mater. Interfaces 10, 24816-24828 (2018).

101. Singh, S. K., Akhtar, M. \& Kar, K. K. Impact of $\mathrm{Al}_{2} \mathrm{O}_{3}, \mathrm{TiO}_{2}, \mathrm{ZnO}$ and $\mathrm{BaTiO}_{3}$ on the microwave absorption properties of exfoliated graphite/epoxy composites at X-band frequencies. Compos. B Eng. 167, 135-146 (2019).

102. He, M. et al. Flower-like CoS hierarchitectures@polyaniline organic-inorganic heterostructured composites: preparation and enhanced microwave absorption performance. Compos. Sci. Technol. 200, 108403 (2020).

103. Wang, X. et al. Green approach to conductive PEDOT: PSS decorating magnetic-graphene to recover conductivity for highly efficient absorption. ACS Sustain. Chem. Eng. 6, 14017-14025 (2018).

104. Qin, M., Zhang, L., Zhao, X. \& Wu, H. Defect induced polarization loss in multi-shelled spinel hollow spheres for electromagnetic wave absorption application. Adv. Sci. 8, 2004640 (2021).

105. Lv, H., Zhou, X., Wu, G., Kara, U. I. \& Wang, X. Engineering defects in $2 \mathrm{D}$ g- $\mathrm{C}_{3} \mathrm{~N}_{4}$ for wideband, efficient electromagnetic absorption at elevated temperature. J. Mater. Chem. A. https://doi.org/10.1039/D1TA02785A (2021).

106. Gu, W. et al. Extending effective microwave absorbing bandwidth of CoNi bimetallic alloy derived from binary hydroxides. Sci. Rep. 10, 1-11 (2020).

107. Lv, J. et al. Nanofiber network with adjustable nanostructure controlled by PVP content for an excellent microwave absorption. Sci. Rep. 9, 1-10 (2019).

108. Ibrahim, I. R. et al. A study on microwave absorption properties of carbon black and $\mathrm{Ni}_{06} \mathrm{Zn}_{0.4} \mathrm{Fe}_{2} \mathrm{O}_{4}$ nanocomposites by tuning the matching-absorbing layer structures. Sci. Rep. 10, 1-14 (2020).

109. Shu, R., Li, W., Wu, Y., Zhang, J. \& Zhang, G. Nitrogen-doped Co-C/MWCNTs nanocomposites derived from bimetallic metalorganic frameworks for electromagnetic wave absorption in the X-band. Chem. Eng. J. 362, 513-524 (2019).

110. Zhu, Y. et al. Large-scale preparation of Co nanoparticles as an additive in carbon fiber for microwave absorption enhancement in C band. Sci. Rep. 11, 1-14 (2021).

111. Peymanfar, R. \& Ghorbanian-Gezaforodi, S. Preparation of graphite-like carbon nitride $\left(\mathrm{g}-\mathrm{C}_{3} \mathrm{~N}_{4}\right) / \mathrm{NiCo}_{2} \mathrm{~S}_{4}$ nanocomposite toward salient microwave characteristics and evaluation of medium influence on its microwave features. Nanotechnology 31, $495202(2020)$

\section{Acknowledgements}

This work is supported by Iran Science Elites Federation Grant No. 11/66332.

\section{Author contributions}

R.P.: project administration, supervision, methodology, visualization, resources, conceptualization, data curation, writing-review and editing, drawing Figs. 2, 3, 4, 5, 6, 7, 8, 9, 10, 11, 12 and 14. E.S.-Z.: formal analysis, investigation, resources, drawing Figs. 1 and 13. A.A.: formal analysis, investigation, resources. S.H.T.: project administration, advisor, editing. 


\section{Competing interests}

The authors declare no competing interests.

\section{Additional information}

Supplementary Information The online version contains supplementary material available at https://doi.org/ 10.1038/s41598-021-91370-5.

Correspondence and requests for materials should be addressed to R.P. or S.H.T.

Reprints and permissions information is available at www.nature.com/reprints.

Publisher's note Springer Nature remains neutral with regard to jurisdictional claims in published maps and institutional affiliations.

(c) (1) Open Access This article is licensed under a Creative Commons Attribution 4.0 International License, which permits use, sharing, adaptation, distribution and reproduction in any medium or format, as long as you give appropriate credit to the original author(s) and the source, provide a link to the Creative Commons licence, and indicate if changes were made. The images or other third party material in this article are included in the article's Creative Commons licence, unless indicated otherwise in a credit line to the material. If material is not included in the article's Creative Commons licence and your intended use is not permitted by statutory regulation or exceeds the permitted use, you will need to obtain permission directly from the copyright holder. To view a copy of this licence, visit http://creativecommons.org/licenses/by/4.0/.

(C) The Author(s) 2021 